\title{
System Analysis Applied to Autonomy: Application to High- Altitude Long-Endurance Remotely Operated Aircraft
}

\author{
Larry A. Young ${ }^{1}$ \\ NASA Ames Research Center, Moffett Field, CA, 94035-1000 \\ Jeffrey A. Yetter ${ }^{2}$, and Mark D. Guynn ${ }^{3}$ \\ NASA Langley Research Center, Hampton, VA, 23681-0001
}

\begin{abstract}
Maturation of intelligent systems technologies and their incorporation into aerial platforms are dictating the development of new analysis tools and incorporation of such tools into existing system analysis methodologies in order to fully capture the trade-offs of autonomy on vehicle and mission success. A first-order "system analysis of autonomy" methodology is outlined in this paper. Further, this analysis methodology is subsequently applied to notional high-altitude long-endurance (HALE) aerial vehicle missions.
\end{abstract}

\section{Nomenclature}

$\mathrm{a}_{\mathrm{x}} \quad$ Coefficients, defined in text

Alt Altitude

$c_{t}$ Percent coverage of target in final data product ("image")

$\mathrm{c}_{\mathrm{x}} \quad$ Coefficients, defined in text

$\mathrm{C}_{\mathrm{AS}}$ Autonomous System Complexity

$\mathrm{C}_{\mathrm{EO}}$ Environmental and Operational Complexity

$\mathrm{C}_{\mathrm{GCS}}$ Cost of ground control station

$\mathrm{C}_{\mathrm{m}} \quad$ Cost of mission (if mission prematurely terminated)

$\mathrm{C}_{\mathrm{v}} \quad$ Cost of vehicle (if unexpectedly lost)

$\mathrm{D}_{\mathrm{C}}$ "Discovery confidence" metric for aerial explorers

$\mathrm{D}_{\mathrm{I}} \quad$ "Degree of inaccessibility"

$D_{\text {IN }}$ "Degree of interaction" among UAVs and other intelligent systems to complete a given mission

$\mathrm{D}_{\mathrm{R}}$ "Degree of resistance"

$F_{P} \quad$ Processor speed (instruction or operation)

$\mathrm{F}_{\mathrm{T}} \quad$ Target frequency

GW Gross Weight

$\mathrm{h}_{\mathrm{i}} \quad$ Time by $\mathrm{i}^{\text {th }}$ person on considered tasks, in hours
LOA Level of Autonomy

$\mathrm{m}$ Fraction of mission completed prior to premature termination

$\mathrm{m}_{\mathrm{x}} \quad$ Coefficients, defined in text

M Baseline "staffing" matrix

$\mathrm{n} \quad$ Number of operations personnel

$\mathrm{n}_{\mathrm{x}} \quad$ Coefficients, defined in text

$\mathrm{N}_{\mathrm{B}} \quad$ Number of robotic behaviors

$\mathrm{N}_{\mathrm{C}} \quad$ Number of control actuators

$\mathrm{N}_{\text {DOF }}$ Number of degrees of freedom, robot mobility

$\mathrm{N}_{\mathrm{L}} \quad$ Lines of software code

$\mathrm{N}_{\mathrm{M}} \quad$ Size of system dynamic memory

$\mathrm{N}_{\mathrm{P}} \quad$ Number of processors

$\mathrm{N}_{\mathrm{R}}$ Number of robots (and/or intelligent systems, including autonomous aerial vehicles)

$\mathrm{N}_{\text {Rule }}$ Number of conditional (heuristic) rules

$\mathrm{N}_{\mathrm{S}} \quad$ Number of sensors

$\mathrm{N}_{\mathrm{V}} \quad$ Number of state space variables

$\mathrm{o}(\mathrm{t})$ Obsolescence of data product upon delivery (hours)

$\mathrm{P} \quad \mathrm{MTBF}$ (mean time between failure) $\mathrm{x}$ mission

\footnotetext{
${ }^{1}$ Aerospace Engineer, Flight Vehicle Research and Technology Division, Mail Stop 243-12, AIAA senior member.

${ }^{2}$ Deputy Project Manager, NASA Vehicle Systems Program, Mail Stop 254, AIAA member.

${ }^{3}$ System Analyst, NASA Vehicle Systems Program, Mail Stop 442, AIAA senior member.
} 
duration

q Production quantity of HALE aircraft of a particular type/mission

Q QFD-inspired technology-to-goals matrix

$r_{t} \quad$ Resolution adequacy of target image (0 to 1)

$\mathrm{R} \quad$ Factor for consequence of failure; values for types of events: return to base $=0$; damage to aircraft $=$ (cost to repair)/(vehicle cost); crash in unpopulated area $=2$ (loss of vehicle plus retrieval costs); crash into urban area $=100$

$\mathrm{R}_{\mathrm{C}} \quad$ Control input rate

MROI Mission return on investment

$\mathrm{s}_{\mathrm{t}} \quad$ Clarity adequacy of target image (0-1)

S Mission success

t Specific target

$\mathrm{T}$ Mission duration

$\mathrm{T}_{\mathrm{O}} \quad$ Set of observation targets defined by users (as applied to wildfire surveillance missions)

$\mathrm{T}_{\mathrm{Mi}}$ i'th case of $\mathrm{M}$ mission tasks (for multiple coordinated flyers)

$\mathrm{v}_{\mathrm{t}} \quad$ Value from perfect observation of target $\mathrm{t}$

$\mathrm{w}_{\mathrm{i}} \quad$ Wage of $\mathrm{i}^{\text {th }}$ person, $\$ / \mathrm{hr}$ $\alpha_{i} \quad$ Weight factor reflecting importance of overall mission task (as executed by multiple, coordinated flyers)

$\beta_{\mathrm{i}} \quad$ success of individual task, (as executed by multiple, coordinated flyers)

$\gamma \quad$ Discount factor for data obsolescence (percent loss value per hour)

$1 \quad$ Aerial vehicle intelligence metric

$\varepsilon \quad$ Aerial vehicle autonomous system implementation elegance metric

$\xi \quad$ Telecom relay messages per aircraft per day

$\zeta \quad$ Station-keeping science observations per day

$\aleph$ Level of Autonomy (LOA), $0 \leq \aleph \leq 5$, "aleph"

Superscript:

* "Normalized" metrics of vehicle intelligence, elegance, and degrees of inaccessibility, resistance, and interaction, such that range of value of parameters fall within 0 and 10 .

\section{Introduction}

SYSTEM analysis is an essential technical discipline for the modern design of aerial vehicles and their associated missions. Specifically, system analysis is a powerful aid in identifying and prioritizing the required technologies needed for mission and/or vehicle development efforts. Maturation of intelligent systems technologies, and their incorporation into aerial platforms, is dictating the development of new analysis tools, and incorporation of such tools into existing system analysis methodologies, in order to fully capture the tradeoffs of autonomy on vehicle and mission success. A first-order "system analysis of autonomy" methodology will be outlined in this paper. Further, this analysis methodology will be applied to a set of notional high-altitude long-endurance (HALE) uninhabited aerial vehicle (UAV) missions.

For planetary flight vehicles (PFV), a high level of autonomy is essential to accomplish their missions. The substantial time delay in interplanetary communications makes aerial vehicle autonomy a necessity. For terrestrial uninhabited aerial vehicles (UAV), though, autonomy (above that of teleoperation, or rather simple remotely piloted vehicle capability) is not essential but, nonetheless, could be a powerful enabling technology. Other than the most qualitative of assessments, how can cost/benefit analysis for incorporation of autonomous system technologies into aerial vehicles be performed? The first step needs to be the definition of metrics for autonomy that are indeed unambiguous and quantifiable.

Fundamental concepts such as autonomy, intelligence, and elegance for planetary flight vehicles (a.k.a. aerial explorers) have been earlier presented ${ }^{1}$. In many respects, these autonomy metrics needed to be uniquely tailored for aerial explorers. In the case of terrestrial UAVs, previously proposed ${ }^{2}$ autonomous control levels (ACL) have been more generally accepted. The NASA Vehicle Systems Program (VSP) HALE Sector concluded that the DOD/AFRL ACL were too extensive (too many and too nuanced) for the envisioned HALE science missions. A simplified set of level of autonomy (LOA) metrics have therefore been adopted by the VSP HALE Sector.

Once having defined quantifiable autonomy metrics for UAVs, reasonable first-order functional relationships are defined relating vehicle and mission characteristics to aforesaid autonomy metrics, and ultimately related to individual autonomous system technologies. Hopefully, this preliminary "system analysis for autonomy" methodology, though still somewhat conjectural, will serve as a starting point for a robust future discussion of an important nascent area of engineering investigation. 


\section{A. Autonomy - keep it simple}

What is this "autonomy" all about? It is about taking the human out of the airplane. Not completely out of the loop, but minimizing human involvement in the operation of the vehicle while providing enhanced mission flexibility and vehicle robustness. UAVs will be operated for durations exceeding the physical capabilities of a human operator and the cost of operating the vehicle can be minimized by reducing the work load required to a level sufficient that numerous aircraft may be operated by a single operator. The AIAA defines autonomy as "A systems own ability of sensing, perceiving, analyzing, communicating, planning, decision-making, and acting, to achieve its goal as assigned by human operators". ${ }^{23}$ However this does not provide the perspective for collaborative vehicle operations where UAVs will eventually excel. To address this issue numerous organizations have attempted to define autonomy in terms of a Level of Autonomy (LOA). In most cases the proposed LOA become complicated and address vehicle capabilities beyond those needed for typical science and civil applications. Since no readily applicable LOA definition existed that exactly matched the VSP HALE Sector envisioned operational aspects of HALE UAVs, the Sector established its own definition.

Table 1 defines the LOA used by the HALE Sector to articulate its autonomy goals and objectives. Important in the definition of the LOA is the concept of "hands-on-time". Hands-on-time is defined as the percentage of a pilot's time (direct attention paid to the UAV) that would be required to safely operate the UAV during a given mission. Hands-on-time is limited to the pilot/operator and does not include other mission personnel (e.g., sensor/payload operator). Nominal values are presented in the table, actual hands-on-time will vary with the mission.

What are the primary autonomy enablers? To be able to fly in civil airspace you need an UAV system with a demonstrated Equivalent Level of Safety (ELOS) as a manned system. It cannot cost any more to operate than a manned system. In fact, one should be able to realize a cost reduction through automation. The primary challenges (hurdles) to achieving these fundamental desired features are: system safety and reliability (addressing airworthiness, sense \& avoid, and validation \& verification); fault tolerant system architectures (providing robustness, situational awareness, automated operations); contingency management (fault detection, prognostics, emergency procedures); and other miscellaneous factors such as software certification, ELOS certification, and Air Traffic Management (ATM) interfaces with manned and other unmanned assets.

\section{B. Various Notional HALE Missions and Overall Characteristics}

The NASA VSP is in the process of completing a survey of potential civilian UAV missions - including High Altitude Long Endurance (HALE) science platforms. ${ }^{16}$ Some of the notional missions are summarized in Table 2. These representative missions will be referred to in later sections of the paper - particularly in the context of benchmarking UAV autonomy metrics and establishing functional relationships for the proposed "system analysis for autonomy" methodology. 
Table 1. Levels of Autonomy adopted by the VSP HALE Sector

\begin{tabular}{|c|c|c|c|}
\hline LOA & Level & Description (Features) & Sample Characteristics \\
\hline 0 & $\begin{array}{l}\text { Remote } \\
\text { Controlled }\end{array}$ & $\begin{array}{l}\text { Remotely piloted aircraft with a human in the loop, making all } \\
\text { the decisions. Operator is in constant control. (100\% hands- } \\
\text { on-time.) }\end{array}$ & $>\mathrm{R} / \mathrm{C}$ airplane \\
\hline 1 & $\begin{array}{l}\text { Simple } \\
\text { Automation }\end{array}$ & $\begin{array}{l}\text { Remotely piloted with some automation techniques to reduce } \\
\text { pilot workload. Human monitoring to start/stop tasks. ( } 80 \% \\
\text { hands-on-time.) }\end{array}$ & $>$ Basic autopilot \\
\hline 2 & $\begin{array}{l}\text { Remotely } \\
\text { Operated }\end{array}$ & $\begin{array}{l}\text { Human operator allows UAV on-board systems to do the } \\
\text { piloting. As part of the outer control loop, the human makes } \\
\text { decisions as to where to go, when, what to do once there. } \\
\text { Remotely supervised, with health monitoring and limited } \\
\text { diagnostics. Operator allows UAV to execute preprogrammed } \\
\text { tasks, only taking over if the UAV is unable or fails to } \\
\text { properly execute them. (50\% hands-on-time.) }\end{array}$ & $\begin{array}{l}\text { Integrated Vehicle } \\
\text { Health Management } \\
\text { (IVHM) } \\
>\text { Onboard Contingency } \\
\text { Management } \\
\text { capabilities } \\
>\text { Waypoint navigation } \\
\end{array}$ \\
\hline 3 & $\begin{array}{l}\text { Highly- } \\
\text { Automated } \\
\text { or } \\
\text { Semi- } \\
\text { Autonomous }\end{array}$ & $\begin{array}{l}\text { UAV automatically performs complex tasks. System } \\
\text { understands its environment (situational awareness) and } \\
\text { makes routine decisions and mission refinements to } \\
\text { dynamically adjust to flight and mission variables. Limited } \\
\text { human supervision, managed by exception. Adaptive to } \\
\text { failures and evolving flight conditions. ( } 20 \% \text { hands-on-time.) }\end{array}$ & $\begin{array}{l}\text { > Loss-link mission } \\
\text { continuation } \\
>\text { Automatic takeoff/land } \\
>\text { Adaptive control } \\
\text { techniques } \\
>\text { Reactive "search and } \\
\text { find" terrain recognition }\end{array}$ \\
\hline 4 & $\begin{array}{l}\text { Fully } \\
\text { Autonomous }\end{array}$ & $\begin{array}{l}\text { UAV receives high-level mission objective (e.g., location, } \\
\text { time), translates them into tasks that are executed without } \\
\text { further human intervention. UAV has the ability and } \\
\text { authority to make all decisions. Extensive situational } \\
\text { awareness (internal and external), prognostics, and on-board } \\
\text { flight re-planning capability. Single vehicle operations. (Less } \\
\text { than 5\% hands-on-time.) }\end{array}$ & $\begin{array}{l}>\text { Automated in-flight re- } \\
\text { planning } \\
>\text { Mission sensor-directed } \\
\text { operations }\end{array}$ \\
\hline 5 & $\begin{array}{l}\text { Collaborative } \\
\text { Operations }\end{array}$ & $\begin{array}{l}\text { Brings in aspects of multiple UAVs working autonomously } \\
\text { together as a collective intelligent system. Group } \\
\text { coordination. Individual vehicles/systems in a collaborative } \\
\text { group will have a least semi-autonomous LOA (3) to keep the } \\
\text { operator workload of the collaborative operation at a } \\
\text { manageable level. (Total hands-on-time for sum of all air } \\
\text { vehicles would not exceed a single operator hands-on-time of } \\
100 \% \text {.) }\end{array}$ & $\begin{array}{l}>\text { Cooperative and } \\
\text { collaborative flight } \\
>\text { Mother- and daughter- } \\
\text { ship collaborative } \\
\text { operations } \\
>\text { Team leader concept for } \\
\text { cooperative systems } \\
>\text { Robotic swarms }\end{array}$ \\
\hline
\end{tabular}


Table 2. Representative (Notional) HALE Missions

Telecom Relay Platform Mission/fight profile: transit from local commercial airport to station-keeping altitude ( $>60 \mathrm{~K} \mathrm{ft}$ ), long duration loiter (>30 days). Critical capability: flight endurance and payload capacity. Technical challenges: power and propulsion; reliability. Autonomous system technology challenges: highly autonomous operations during station-keeping, autonomous payload management, and health monitoring and prognostics of flight systems. Automated piloting to and from station-keeping altitude. Risk/hazard: disruption of services.

Severe Storm-Tracker Mission/fight profile: launch/recovery from regional centers; mid-altitude $(40 \mathrm{~K}<\mathrm{Alt}<60 \mathrm{~K} \mathrm{ft})$ long-range $(>1000 \mathrm{~km})$ cruise to operational area; increase altitude $(>60 \mathrm{kft})$ and engage/track storm for duration (4 to 10 days). Critical capability: robust structural and aero-handling characteristics to fly in moderate turbulence. Autonomous system technology challenges: adaptive flight controls (e.g., aero-handling, potential control surface failure); science payload management; sensor/payload-driven in-flight re-planning (e.g., onboard lidar/radar tracking of immediate-vicinity storm patterns and velocity flow-fields) for flight path management and goal-based decision-making. Risk/hazard: loss of aircraft due to severe weather conditions.

Border \& Coastal Patrol Mission/fight profile: launch/recovery from a regional center, cruise at mid-altitude $(40 \mathrm{~K}<$ Alt $<60 \mathrm{~K} \mathrm{ft})$, long-range $(>1000 \mathrm{~km})$, and moderate duration (4 to 10 days). Critical capability: stable flight platform with high-resolution imaging/sensing capability and ability to traverse large survey areas. Autonomous system technology challenge: science payload management; real-time re-planning; secure, high-bandwidth data relay/networking. Risk/hazard: inability to acquire and transfer critical intelligence to appropriate decisionmakers in a timely manner. See Ref. 22.

Station-Keeping Science Platform - observation of persistent science phenomenon; e.g., monitoring volcanoes, polar "ozone holes," environmental effects of chemical spills and toxic ocean "blooms," etc. Mission/flight profile: deploy from national science centers, transit to station-keeping altitude $(>60 \mathrm{~K} \mathrm{ft})$, long duration loiter (>30 days). Critical capabilities: long endurance, low-speed loiter capability coupled with large payload capacity. Autonomous system technology challenge: automated mission operations during station-keeping including science payload management. Risk/hazard: disruption of services.

Long-Range Science \& Surveillance Platform - observation of transient and/or widely-distributed phenomenon; e.g., damage surveys and coordination for large-scale disasters such as earthquakes and hurricanes; tracking migration patterns of animals/insects; mapping/measuring the spatiotemporal variation of air and ocean currents; assessing compliance of international laws/regulations over international waters, e.g. prohibition on whale harvesting. Mission/flight profile: long-range $(>1000 \mathrm{~km})$, moderate duration (4 to 10 days), moderate altitude $(40 \mathrm{~K}<\mathrm{Alt}<60 \mathrm{~K} \mathrm{ft})$ cruise capability; navigation by pre-planned GPS waypoints and sensor/science-driven decision-making. Autonomous system technology challenges: sensor/science-driven navigation and goal-based decision-making. Risk/hazard: inability to acquire and transfer critical data/information to appropriate users/decision-makers in a timely manner.

Sensor-Network Aerial Constellation - repeat pass interferometry (RPI), military and civilian search and find (complementing manned rescue aircraft), dropsonde deployment. Mission/fight profile: multiple UAVs conducting coordinated (simultaneous) flights to achieve single mission goal. Critical capability: near-real-time or better fusion of data/information from multiple aircraft (and other assets). Technical challenge: repeated precision over-flight of critical waypoints/trajectories. Autonomous system technology challenge: vehicle-tovehicle, vehicle-to-ground-control, and vehicle-to-other-intelligent-systems coordination (and in some cases "negotiation"). Risk/hazard: operational difficulties in managing multiple assets; hazard/collision avoidance.

Wildfire Surveyor - satellite monitoring of critical areas is used to pre-plan and launch UAV assets from a few national/regional centers to perform real-time monitoring of fire propagation as well as provide coordination information for firefighting ground crews and manned aircraft; Mission/fight profile: high-speed (>100 knots) mid- to high-altitude flight $(40 \mathrm{~K}<\mathrm{Alt}<60 \mathrm{~K} \mathrm{ft})$, long-range capability $(>1000 \mathrm{~km})$; short duration $(1 \mathrm{day})$. Critical capability: real-time re-tasking/re-planning. Technical challenge: cost-effective on-demand asset reliability/availability. Autonomous system technology challenges: intelligent mission management; data \& information networking. Risk/hazard: inability to acquire and transfer critical intelligence to appropriate decision-makers in a timely manner.

Aerial Explorers - planetary aerial surveys, surface interactive through drop probes and small robotic devices, and possibly vertical take-off and landing (VTOL) capability. Non-GPS navigation required. See reference 1. 
By way of illustration, Fig. 1 is a notional concept of a 14-day endurance HALE platform being studied by the NASA HALE Sector. Figure 2 is a notional concept of a 100-day endurance vehicle. The two notional HALE flyers also represent a spectrum of mission capabilities, vehicle design, and technology challenges. Both of these HALE platforms could satisfy a number of the Table 2 missions. The autonomous system technology challenges will be the primary focus of discussion as related to these vehicles and their range of mission applications.

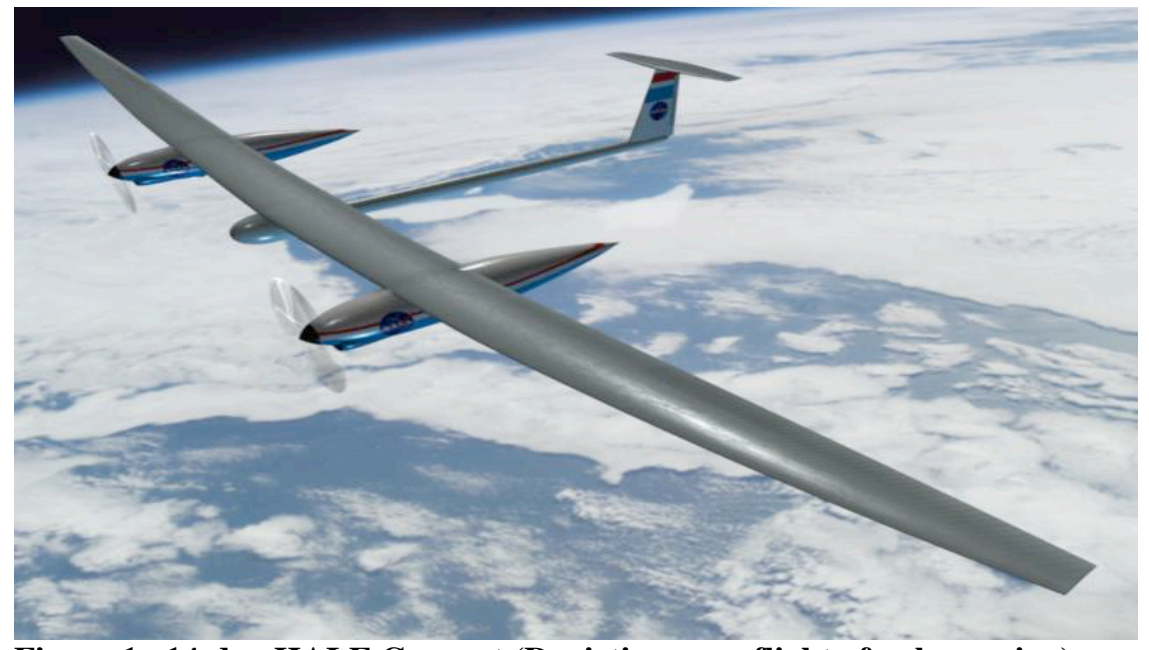

Figure 1. 14-day HALE Concept (Depicting over-flight of polar region)

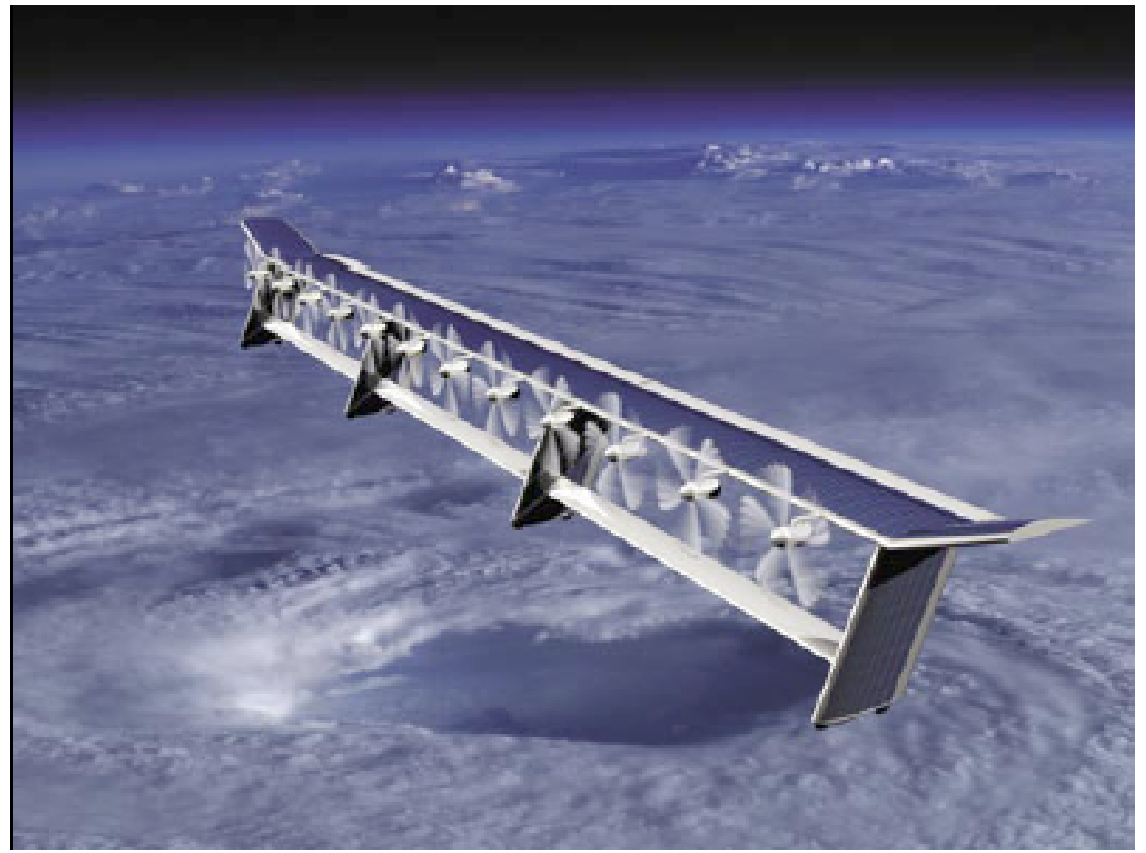

Figure 2. 100-day HALE Concept (Depicting over-flight of hurricane) 


\section{Fundamental Questions about UAV Autonomy}

In respect to HALE UAV autonomy, there are several fundamental vehicle autonomy questions that need to be addressed by system-analysis-type trade studies. Among these questions are:

- Is there a way to identify "breakthrough" UAV missions/applications where autonomy is a key technology enabler?

- How much, and what type/level of, autonomy is appropriate for certain missions and applications? E.g., is there a need for autonomous capability greater than teleoperation (i.e. remote-piloting) for HALE UAV?

- For a given mission/application and appropriate associated autonomy level, what is the minimum required level of intelligence and elegance (efficiency of the intelligence implementation/realization) to yield acceptable mission success, cost, and reliability thresholds? What, if any, are the negative consequences of building in too much autonomy and intelligence into an aerial vehicle?

Ancillary questions to the above cost/benefit question can be posed for certain intelligent sub-systems above and beyond the vehicle autonomy implementation itself.

- How much cumulative "autonomous system technology" development cost is acceptable before human operation is more cost effective?

- What is the breakeven cost for development implementation of intelligent onboard prognostics/diagnostic systems, given certain assumed missions? And, further, what is the breakeven cost of development and implementation of intelligent/adaptive flight control systems?

- What is the cost/benefit trade between autonomous system elegance (computational efficiency and avionic system complexity) and vehicle reliability and safety?

\section{HALE UAVs and the Impact of Autonomy}

Autonomous systems technologies find their greatest utility not in just replacing onboard pilots, engineers, and scientists with ground-based operators/monitors, but with expanding into new application domains and enabling wholly new mission applications. A number of these new mission applications, both terrestrial and planetary, were presented in Table 2. However, it is also important to note that the greatest impact of autonomous system technology is not limited to its implementation on a single aerial platform, or even multiple versions of a single vehicle type, but rather the greatest impact will result from the application of autonomy to heterogeneous robotic systems working in cooperation/collaboration with each other to achieve mission success. Figures $3 \mathrm{a}$ and $3 \mathrm{~b}$ show two examples of the simplest form of cooperating system of robotic assets: the deployment of "intelligent" dropsondes from a terrestrial UAV and mid-air-deployment of "robotic symbiotes" from a planetary aerial explorer. Many such coordinated and cooperating systems of robots, including/incorporating UAV aircraft, can and have been conceived in principle. In an ideal sense unmanned aerial vehicles do not merely replace manned aircraft, but are in fact true aerial robots.

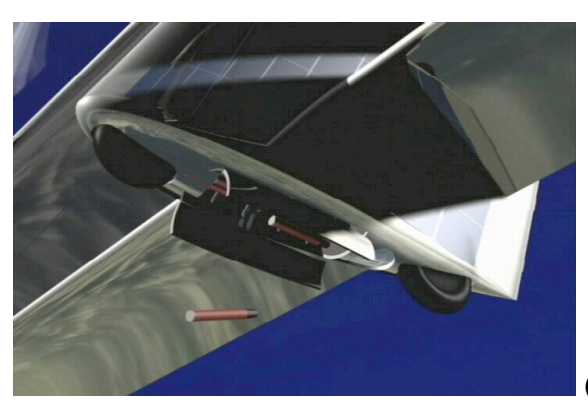

(a)

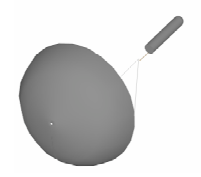

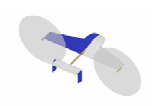

(b)

Figure 3. Examples of Collaborative Operations: (a) dropsonde from HALE "storm tracker" and (b) planetary aerial explorer and air-deployed robotic symbiote 


\section{The Proposed Basic Methodology}

The basic "system analysis of autonomy" methodology is outlined in this section. Figure 4 presents a high-level flow chart of the proposed methodology. Each element of the method will be discussed in detail.

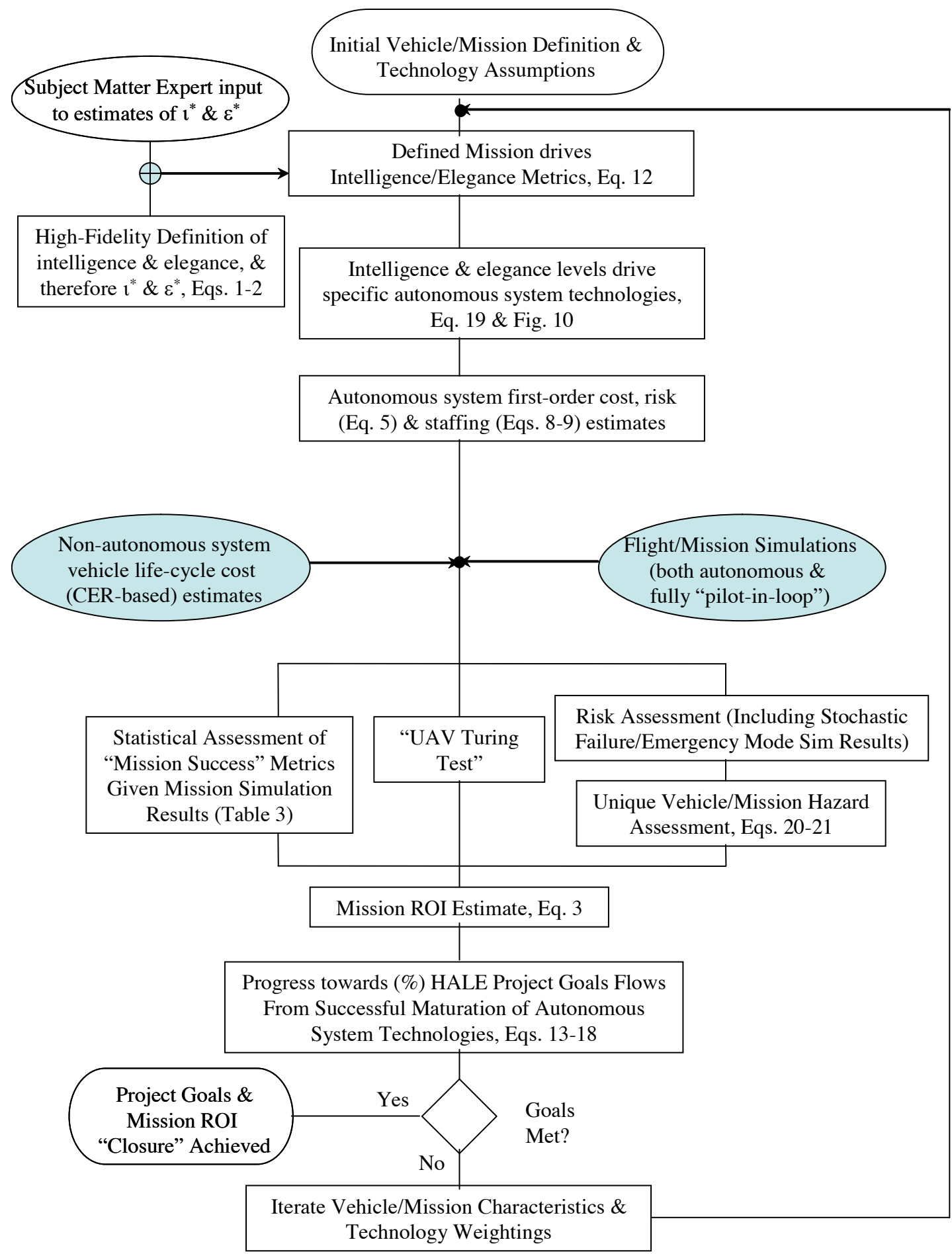

Figure 4. System Analysis Flow Chart 


\section{A. Statement of Problem}

The problem to be studied is easy to describe but difficult to solve:

- First, what is the optimum level of vehicle autonomy and intelligence required for a particular HALE UAV mission/application, so as to assure acceptable levels of success and safety while at the same time keeping development and implementation costs to a minimum?

- Second, what are the specific attributes of an autonomous system implementation essential for a given mission/application and aerial vehicle in order to maximize mission success?

The engineering community must be careful not to imbue systems with unnecessary, or otherwise inappropriate, levels of autonomy and intelligence for the particular purposes to which they are applied. To draw on examples from science fiction, there is no need for talking toasters ${ }^{\mathrm{a}}$ or smart bombs that pose existential questions $\mathrm{b}^{\mathrm{b}}$. Similarly, aircraft should not be able to decide that they would rather fly to Palm Springs than Seattle -- for the better weather - on any given day or flight. (Such decision-making freedom, though, may well be appropriate for a planetary aerial vehicle, so as to enable "serendipitous science" and missions of opportunity.)

\section{B. Concepts and Initial Metrics}

Considerable work has been documented in the literature as to machine intelligence metrics; however, only modest work has been dedicated to UAVs. ${ }^{20-21}$ Delving briefly into the autonomy versus intelligence debate, autonomy is defined for the purposes of this paper as the ability to independently perform without human intervention actions, tasks, or roles. Intelligence measures how well these actions, tasks or roles are performed under varying degrees of task and environmental complexity and other associated constraints and conditions. And, elegance is the computational efficiency by which the autonomous vehicle intelligence is implemented. Therefore, it is wholly possible that two robotic systems can be at nominally equivalent autonomy levels but exhibit radically different levels of intelligence. For example, one robot (aerial or otherwise) could perhaps only perform its tasks in a simple invariant environment, whereas the other robotic system could perform those nominally same tasks in a highly uncertain, unknown, or changing environment. The latter robotic system is clearly more intelligent than the robot that can only successfully operate in the simpler environment, though their autonomy levels may be equivalent. The following concepts and analysis builds upon earlier autonomous aerial vehicle work. ${ }^{1,11-14,18}$

In a simplistic sense, the definitions of intelligence and elegance used in this paper can be expounded upon by examining the following relationships, Eqs. (1a-d), for a given set autonomy level:

$$
\text { Intelligence } \equiv \text { Mission Success } \times \frac{\text { Environmental \& Operational Complexity }}{\text { Number of Robots }}
$$

Or, alternatively,

$$
\imath=\frac{S C_{E O}}{N_{R}}
$$

Correspondingly,

$$
\text { Elegance } \equiv \frac{\text { Intelligence }}{\text { Autonomous System Complexity } \times \text { Number of Robots }}
$$

\footnotetext{
a "Red Dwarf" BBC television show.

b "Darkstar" cinematic film.
} 
Or

$$
\varepsilon=\frac{l}{C_{A S} N_{R}}
$$

Where for autonomy levels $3-5$, at least, which is the primary focus of the current work, the following holds true:

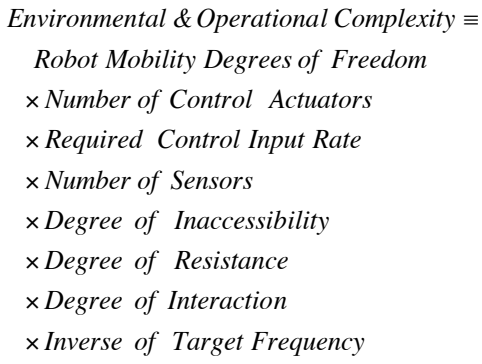

Or, alternatively,

$$
C_{E O}=N_{D O F} N_{C} R_{C} N_{S} D_{I} D_{R} \frac{D_{I N}}{F_{T}}
$$

And

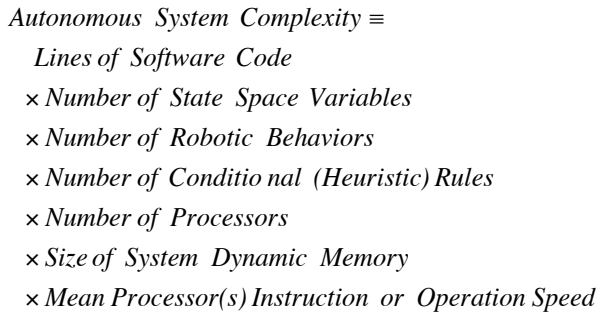

Or, rather,

$$
C_{\text {AS }}=N_{L} N_{v} N_{B} N_{\text {Rule }} N_{P} N_{M} F_{P}
$$

Note that in the expression for "environmental and operational complexity" in Eq. (2a-d) the "degree of inaccessibility" term can encompass many things. In its simplest form, it is equivalent to terrain ruggedness, i.e. unity plus the variance of terrain elevation obscuring features of interest or impeding mobility (as in nap of the earth flight). Also, the "degree of resistance" term can encompass many things, but, again in its simplest form, it is equivalent to atmospheric turbulence, i.e., unity plus the variance in wind magnitude and direction as affecting the ease of flight control. The "degree of interaction" term encompasses the physical (instruments, dropsondes, robotic symbiotes, and other intelligent systems) and informational interactions of the aerial vehicle with objects/features of interest on the ground or interactions with external intelligent systems and/or other members of a robotic ecosystem. In its simplest form for aerial vehicles it is unity plus the resultant of the number of probes and symbiotes released by the aerial vehicle times the post-flight "persistence" of those probes and symbiotes. Finally, the "inverse of target 
frequency" term, for discrete targets, is given by $\pi \mathrm{R}_{\max }^{2} / \mathrm{N}_{\text {Actual }}$ (i.e., the inverse of the number of targets within, and divided by, a maximum potential survey area described by a circle having a radius equal to the maximum range of the aerial vehicle). Note, however, that alternate expressions are required for distributed and scarce targets.

"Mission return on investment" (MROI) can be expressed as

$$
M R O I=\frac{\text { Mission Success }}{\text { Risk } \cdot \text { Cost }}
$$

Note that for the special case of planetary science missions ${ }^{1}$ - where mission cost is effectively capped, the cost can be treated as fixed.

An earlier discussion of risk and cost has been presented in the context of aerial explorers ${ }^{18}$, particularly as related to the question of MSS versus FCL (Many, Simple, Small versus Few, Complex, Large) robotic exploration systems. Based on this early work, a measure of mission "return" for a purely scientific endeavor can be defined by the relationship (i.e. where mission success is proportional to the amount of information gathered):

$$
\text { MROI } \rightarrow \text { Mission Return }=\frac{\text { Information Gathered }}{\text { Risk }}
$$

Where

$$
\begin{aligned}
& \text { Information Gathered }= \\
& \text { Number of sensors } \\
& \text { X Measure of spatio - temporal dispersal of sensors } \\
& \text { X Mean sophistication of sensors } \\
& \text { X Number of different types of sensors } \\
& \text { X Ability to interprete/adapt given past results } \\
& \text { X Ability to verify results } \\
& \text { X Ability to cross - correlate independent measurements }
\end{aligned}
$$

And the inverse of risk is

$$
\begin{aligned}
& \text { 1/Risk }= \\
& (1-\text { Mean probability of sensor failure }) \\
& \text { X Mean probability of sensor successful dispersal } \\
& \text { X Mean probability of communicating data back to Earth }
\end{aligned}
$$

Table 3 notes a number of different measures/metrics for estimating/tracking mission success that can be defined. Each mission application domain (niche) has its own unique mission success metric (though there are certain common constituent elements). Assessing overall mission success needs to be established through a combination of flight test and mission simulation. This will be discussed subsequently in the context of autonomous system technology validation. 
Table 3. Mission Success Metrics for Various Notional Missions

\begin{tabular}{|c|c|}
\hline Mission & Mission Success Metric \\
\hline Telecom Relay Platform & Mission Success $\propto \xi q T$ \\
\hline Storm-Tracker & Mission Success $\propto \zeta c_{t} v_{t} r_{t} s_{t} D_{I} D_{R} D_{I N} T$ \\
\hline Border \& Littoral Water Patrol & MissionSuccess $\propto \zeta c_{t} v_{t} r_{t} s_{t} D_{I} T+D_{C}$ \\
\hline Station-Keeping Science Platform & Mission Success $\propto \zeta v_{t} r_{t} s_{t} T$ \\
\hline Long-Range Science Platform & Mission Success $\propto \zeta c_{t} v_{t} r_{t} s_{t} D_{I N} T+D_{C}$ \\
\hline $\begin{array}{l}\text { Sensor-Network Aerial } \\
\text { Constellation }^{21}\end{array}$ & Mission Success $\propto$ Collaborative Gain $=\sum_{i=1}^{N_{R}} \alpha_{i} \beta_{i} T_{M_{i}}$ \\
\hline Wildfire Surveyor $^{17}$ & Mission Success $=\sum_{t=1}^{T_{O}} v_{t} c_{t} r_{t} s_{t}(1-\gamma)^{o(t)}-\left(\sum_{i=1}^{n}\left(h_{i} \cdot w_{i}\right)+P \cdot\left(R \cdot C_{v}+m \cdot C_{m}\right)\right.$ \\
\hline Aerial Explorers $^{1}$ & Intelligence $\propto$ Mission Success $\propto \mathrm{D}_{\mathrm{C}} \propto$ Targets Found Per Hour \\
\hline
\end{tabular}

For PFVs, "mission success" as related to the intelligence metric is directly proportional to the "discovery confidence" metric, $\mathrm{D}_{\mathrm{C}}$, for aerial explorers working in (robotic) isolation".

Note that there are no upper bounds on the above definitions of the mission success, intelligence and elegance metrics. Their maximum values are dependent upon a given set of vehicle, environmental, and mission characteristics -- which, in turn, are subject to refinement as vehicle designs are matured, mission concept of operations (CONOPS) are detailed, and system characteristics are predicted with improved fidelity analysis/simulation tools and/or measured in flight. Though these autonomy metrics can and should be defined by using the above detailed formulae, a simpler approach should be used when system analysis of vehicle/mission concepts is to be performed. Therefore "normalized versions of system intelligence and elegance, $l^{*}$ and $\varepsilon^{*}$, must be defined where the normalized values fall within the ranges $0 \leq l^{*} \leq 10$ and $0 \leq \varepsilon^{*} \leq 10$. That is, it is posited that there are some notional normalization factors such that $\imath^{*} \equiv l / l_{\text {Constant Factor }}$ and $\varepsilon^{*} \equiv \varepsilon / \varepsilon_{\text {Constant Factor }}$ wherein the above range of values holds true for all realizable HALE UAV missions. In practice, neither quantitative estimates of 1 and $\varepsilon$, or definition of actual values of $l_{\text {Constant Factor }}$ and $\varepsilon_{\text {Constant Factor }}$ need be made in order to gain some advantage from the concept of using normalized measures for these key parameters. The proposed "normalization" is a pragmatic technique that allows engineering judgment to be used in the early stages of the system analysis process, in place of making detailed but difficult estimates of vehicle intelligence and elegance using Eqs. 1-4. Applying representative values for HALE UAVs, the following order of magnitude estimates for the environmental and operational and autonomous system complexity can be made: $\mathrm{C}_{\mathrm{EO}} \approx \mathrm{O}\left(10^{4}\right)$ and $\mathrm{C}_{\mathrm{AS}} \approx \mathrm{O}\left(10^{12}\right)$ - assuming that the dynamic memory is given in terms of MBytes and the processor speeds in GHz. Correspondingly, the normalizing factors are approximately $\iota_{\text {Constant Factor }} \approx O\left(10^{3}\right)$ to $O\left(10^{4}\right)$ and $\varepsilon_{\text {Constant Factor }} \approx O\left(10^{-9}\right)$ to $O\left(10^{-10}\right)$. It is to be expected (as somewhat analogous to human intelligence tests) that the intelligence and elegance metrics will occasionally need to be re-normed with improved mission simulation and autonomous system development results. Correspondingly, the degrees of inaccessibility, $D_{I}$, degrees of resistance, $D_{R}$. and degrees of interaction, $D_{I N}$, can also be "normalized" to range between the values of 0 to 10 and engineering judgment used in place of detailed analysis and mission simulation to define these parameters. 
In the most global sense, mission success, risk, and costs are functions of not only the vehicle LOA, but also the vehicle's intelligence, $\iota$, and elegance, $\varepsilon$, at a given LOA. Mission success, as noted earlier, can only be assessed in terms of flight test and simulation. On the other hand, first-order parametric expressions can be posited for the functionality of risk and cost with respect to a vehicle's intelligence and the elegance of its autonomous system implementation. Specifically, for the purposes of this exercise, it is conjectured that the functional forms for the risk and cost metrics are, respectively, as follows:

$$
\begin{gathered}
\text { Risk } \approx x(T) f\left(l^{*}, \varepsilon^{*}\right) \\
\text { Cost } \approx y(T) g\left(l^{*}, \varepsilon^{*}\right)(1+\aleph)^{m_{0}}
\end{gathered}
$$

Where

$$
\begin{gathered}
f(l, \varepsilon)=\frac{a_{2}\left(\varepsilon^{*}\right)^{-n_{2}}}{a_{1}+\left(l^{*}\right)^{n_{1}}}+a_{3}\left(l^{*}\right)^{n_{3}} \\
g(l, \varepsilon)=c_{1}\left(l^{*}\right)^{m_{1}}\left(\varepsilon^{*}\right)^{-m_{2}}
\end{gathered}
$$

And

$$
\begin{gathered}
x(T)=\frac{T}{\left[M T B F_{\text {Vehicle }}+M T B F_{\text {Payload }}+M T B F_{\text {Providing ServicelData }}\right]} \\
y(T)=\left(C_{v}+C_{m}\right)\left[1+a_{4} \frac{T}{M T B F_{\text {Vehicle }}}\right]
\end{gathered}
$$

Note that $\mathrm{T}$ is the mission duration. The "non-autonomy-related vehicle, payload, or service interruption risks are encapsulated in the functions $\mathrm{x}(\mathrm{T})$ and $\mathrm{y}(\mathrm{T})$, which are directly proportional to mission duration, $\mathrm{T}$. In effect, Eq. $5 \mathrm{a}-\mathrm{f}$ can be considered a generalization of early work for aerial explorers and planetary robotic systems ${ }^{1,18}$. In particular, note the parallel between Eq. 5e, intended for terrestrial HALE-type UAVs, and Eq.4c for planetary aerial explorers. In other words, the probability of sensor failure is analogous to the mean time between failure (MTBF) for the payload system(s). The mean probability of unsuccessful sensor dispersal is analogous to the MTBF of the vehicle (and/or mid-air-deployment of surface interactive payloads). And, finally, the mean probability of unsuccessful data relay to Earth is analogous to MTBF related to service interruption for a terrestrial UAV. The coefficients $\mathrm{a}_{1}, \mathrm{a}_{2}, \mathrm{a}_{4}, \mathrm{n}_{1}$ to $\mathrm{n}_{3}, \mathrm{c}_{1}, \mathrm{~m}_{0}$ and $\mathrm{m}_{2}$ in Eq. $5 \mathrm{a}-\mathrm{f}$ are initially assumed to be equal to unity (i.e. have a value of one). Note though that $\mathrm{a}_{3} \ll \mathrm{a}_{2}$, in this case then a value was assigned where $\mathrm{a}_{3}=0.005$; this constant in the proposed risk function, Eq. 5c, accounts for the possibility that the vehicle might unnecessarily be too "intelligent" for its intended LOA and mission application. These constants will need to be validated in the future with acquisition of vehicle/mission data from actual aircraft operational experience or mission simulations. Such a formulation suggests that there is an optimal combination of aerial vehicle intelligence and elegance for a given LOA and mission application to be sought by means of system analysis accounting for vehicle autonomy. 
Figures 5 and 6 illustrate the proposed trend of the risk and cost metrics, as a function respectively of UAV normalized intelligence and autonomous system implementation elegance, at a given LOA. As can be seen in both Figs. 5 and 6, increasing elegance, in general, reduces risk and cost. Increasing vehicle intelligence reduces risk (except for the slight increase at the high values to reflect potential unnecessary levels of intelligence) but at a price, increased vehicle cost.

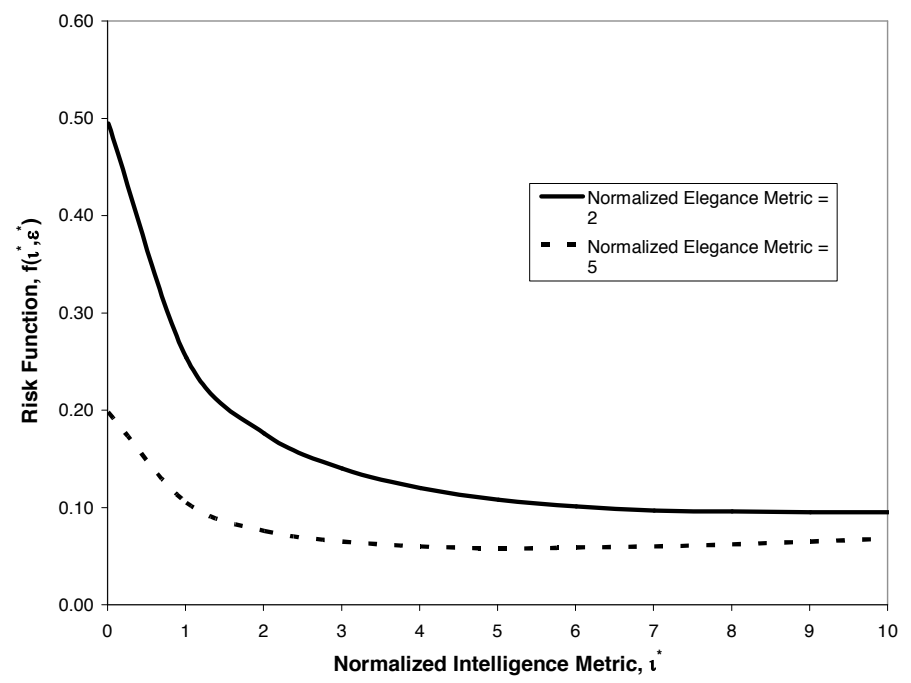

Figure 5. Trend behavior of proposed risk function, $f(t, \varepsilon)$

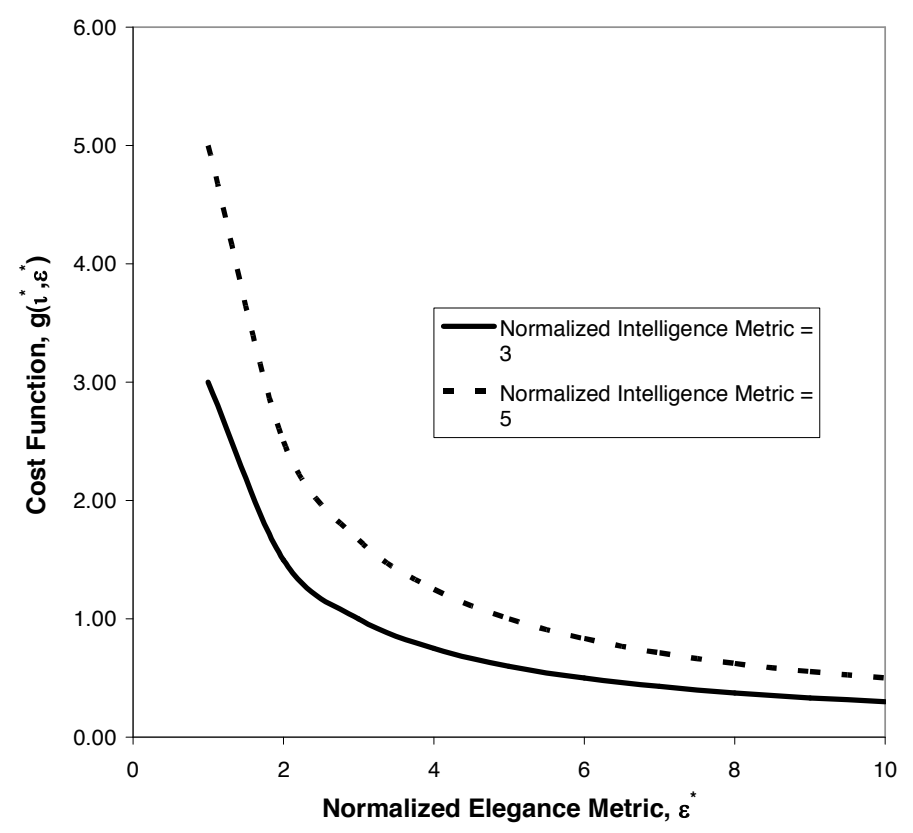

Figure 6. Trend behavior of proposed cost function, $\mathrm{g}(\mathrm{l}, \varepsilon)$ 


\section{Autonomy, Operational Staffing \& Ground Control Costs}

Referring back to Table 1, the trade-off between vehicle autonomy and the amount of human operator "handson-time," $\mathrm{H}_{0}$, and the number of operators per aircraft, $\mathrm{N}_{0}$, can (using the VSP HALE Sector autonomous operations goals and LOA definitions) be expressed in terms of the vehicle level of autonomy, $\aleph$, as

$$
\begin{aligned}
& H_{0}=h(\aleph)=a_{0}+a_{1} \aleph+a_{2} \aleph^{2}+a_{3} \aleph^{3} \\
& N_{0}=b_{0}-\left[b_{1} u(\aleph-2)+b_{2} u(\aleph-5)\right]
\end{aligned}
$$

Where the coefficients are given by $\mathrm{a}_{0}=1.0, \mathrm{a}_{1}=-0.119, \mathrm{a}_{2}=-0.102, \mathrm{a}_{3}=0.018, \mathrm{~b}_{0}=2, \mathrm{~b}_{1}=1$, and $\mathrm{b}_{2}=0.5$; the Eq. $6 \mathrm{a}$ polynomial curve-fit coefficients are derived from least-squares regression of the Table 1 LOA operator "hands on time" limits. The function $\mathrm{u}(\mathrm{x})$ is the unit step function, where if $\mathrm{x}$ is less than zero then $\mathrm{u}(\mathrm{x})=0$, else $\mathrm{u}(\mathrm{x})=1$. Figure 7 illustrates the operator hands-on-time trend line.

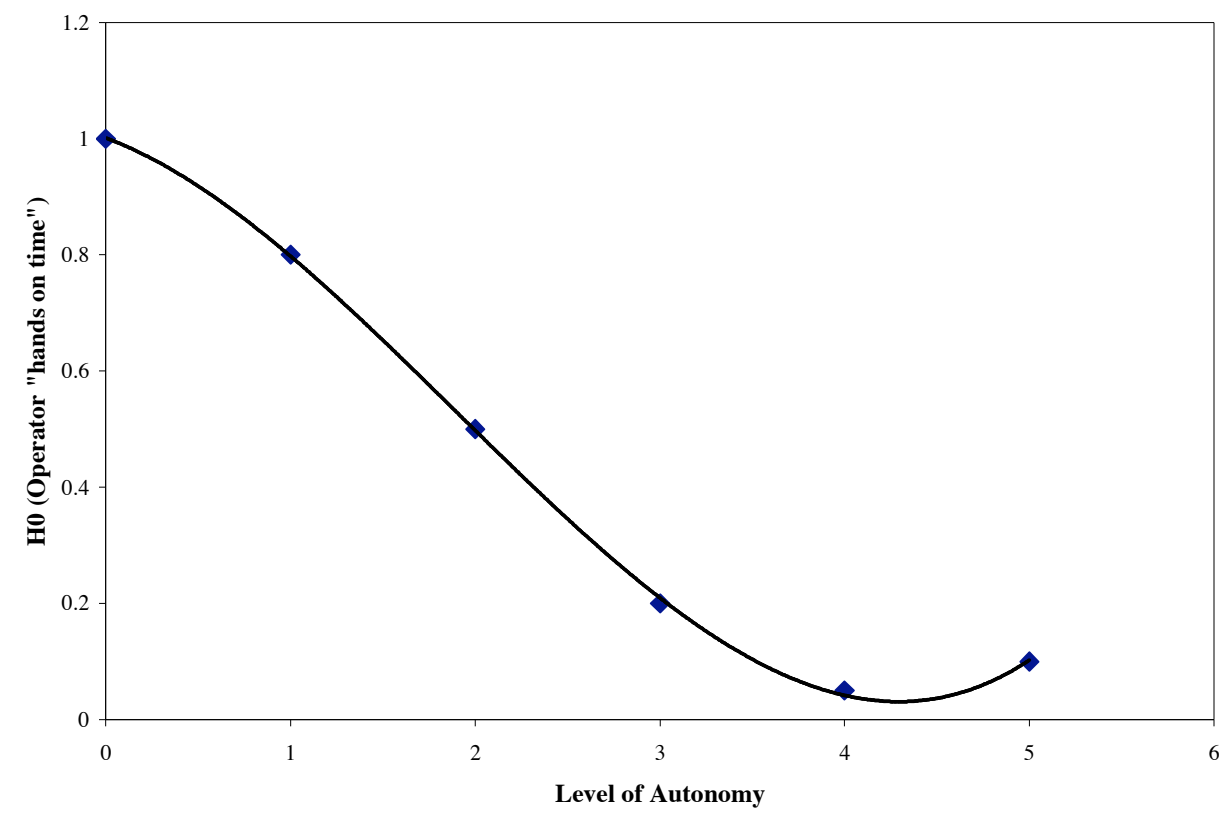

Figure 7. Prescribed Operator "Hands-on-Time" as a function of LOA

In order to estimate the consequences of UAV autonomy, intelligence, and elegance on overall personnel requirements, and not just vehicle operators/pilots, it is necessary to define a baseline operational "staffing" matrix, M, such that

$$
\mathbf{M} \equiv\left[\begin{array}{c}
\text { \# of Vehicle Operators } \\
\text { \# of Flight Engineers \& Monitors } \\
\text { \# of Payload Specialists } \\
\text { \# of Mission Planners/Flight Directors }
\end{array}\right]
$$

As a baseline, an operational "staffing" matrix makes a certain assumption as to level of autonomy, i.e. $\aleph_{B}=2$. This baseline operational staffing vector is populated by constants that are based on generic and/or approximate characteristics of UAVs currently flying. For the purposes of this analysis, the M vector is populated as follows 


$$
\mathbf{M} \rightarrow\left|\begin{array}{l}
b_{0} \\
\beta_{1} \\
\beta_{2} \\
\beta_{3}
\end{array}\right|
$$

Where the constants in the vector $\mathbf{M}$ are $\beta_{1}=1, \beta_{2}=1$, and $\beta_{3}=1$. Note that one might assume that the back-up operator could as act as back-up flight engineer/monitor, however this individual is book-kept only under the operator staffing. Alternate crew staffing can be implemented by changing the values of $\mathbf{M}$.

Now for a given LOA, intelligence, and elegance combination, the following staffing level can be estimated

$$
\mathbf{N}_{i}=\left\{1-\left[\frac{b_{1}}{b_{0}} u\left(\aleph-2-i \cdot\left(1+e^{-b_{3} l^{*} \varepsilon^{*}}\right)\right)+\frac{b_{2}}{b_{0}} u\left(\aleph-5-i \cdot\left(1+e^{-b_{4} l^{*} \varepsilon^{*}}\right)\right)\right]\right\} \mathbf{M}_{i}
$$

The above relationship holds true for $0 \leq \mathrm{i} \leq 4$; when $\mathrm{i}=0$ then Eq. 8 devolves to Eq. $6 \mathrm{~b}$. The newly introduced constants are arbitrarily assigned to be $b_{3}=1$ and $b_{4}=1$. Note that $\mathbf{N}$ and $\mathbf{M}$ are in terms of number of operational personnel per aircraft per operational shift. Equation 8 presupposes a priority phase-in of autonomous system technologies into other operational roles beyond that of operator/pilots.

The HALE UAV maintenance manpower required is handled in a separate manner from that of the operational staffing estimation, but the maintenance support estimates are also affected by autonomy considerations. In this regard, the conventional approach (using a nominal maintenance man hour per flight hour, $\mathrm{MMH} / \mathrm{FH}$, multiplier) to estimate maintenance labor $\operatorname{costs}^{8}$ is modified as follows

$$
\frac{M M H}{F H}=\frac{\aleph \iota^{*} \varepsilon^{*}+b_{5}}{b_{6} \iota^{*} \varepsilon^{*}+1}
$$

Where the constants are $b_{5}=18$ and $b_{6}=1 / 9$ (assuming a 50\% reduction in maintenance labor costs as a consequence of implementing high levels of autonomous system technology).

Finally it should be noted that the total number of operations staff per aircraft per operational shift is given by the simple identity (where $\mathbf{N}$ is given by Eq. 8 )

$$
n=\sum_{i} \mathbf{N}_{i}
$$

Figure 8 illustrates the operational staffing trend as a function of vehicle level of autonomy. 


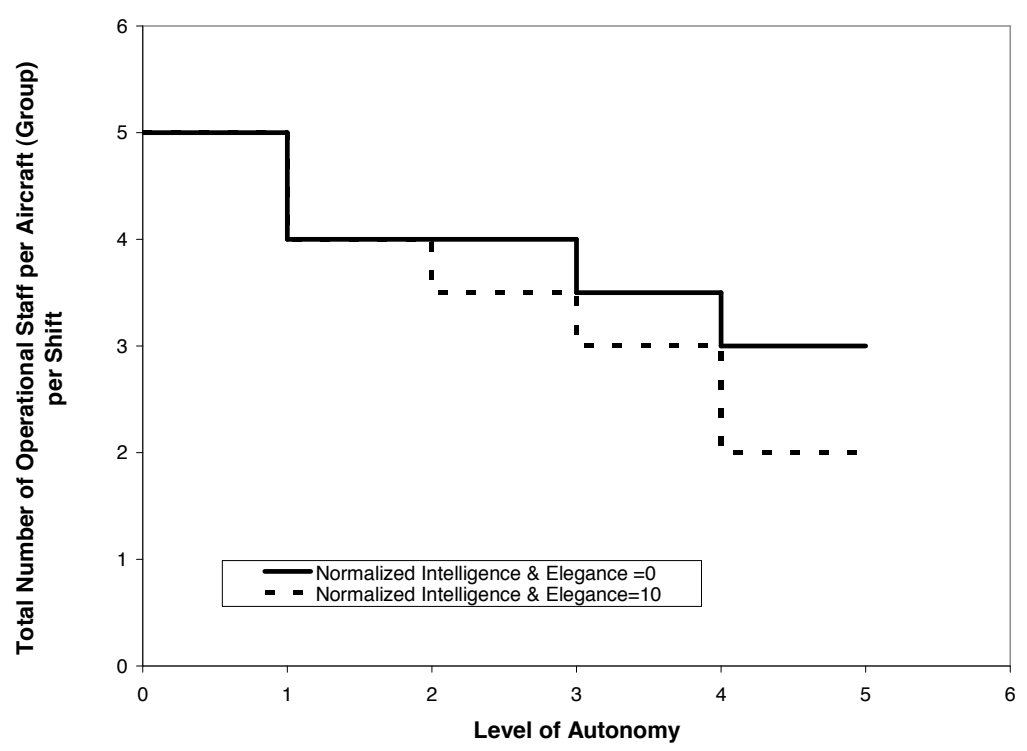

Figure 8. Operational staffing

One UAV-unique technology that sees cost growth with increasing implementation of autonomous system technology is the ground control station, at least at the low- to mid-ranges of such technology. At the highest level of technology, where the vehicle basically runs itself, the need for ground-control sophistication decreases and costs will correspondingly drop as well.

$$
C_{G C S}=a_{0} G W \frac{\aleph^{*} / \varepsilon^{*}}{u(\aleph-4)\left(\aleph^{*}\right)^{2}+a_{1}^{2}}
$$

The basic functionality of the ground control station cost is to assume a conventional cost estimating relationship (CER) approach of dollars per pound of vehicle gross weight, GW. As a baseline, the proportionality constant is assumed to be $\mathrm{a}_{0}=\$ 1000 / \mathrm{lbf}$ (approximately half that of the vehicle avionics cost per pound value ${ }^{8}$ ). However, this simple relationship is also modified by a term accounting for some dependence on level of autonomy. Initially, it is presupposed that including autonomy and overall intelligence into the HALE UAV increases the cost of the control station (employing the logic that a complex system needs another complex system to monitor it, if nothing else); however, at some breakpoint, the autonomy and intelligence of the vehicle becomes so great that the need/ability to monitor/control the vehicle becomes less demanding and the control station costs begin to decrease. (The most extreme example would be a PFV in which no real-time control is exerted over the vehicle and monitoring consists primarily of one way data capture from the vehicle.) Note however that one might consider that increasing the elegance of the autonomous system on the aerial vehicle would reduce the cost of the control station, as a simpler but more robust system needs a less complex system to monitor it. Note that a constant value of $a_{1}=25$ is suggested.

\section{Relationship between Mission Requirements and Autonomy Requirements}

Drawing upon the Table 2 mission descriptions and the Table 3 mission success metrics, Table 4 summarizes an assessment, using engineering judgment at this point of the analysis, as to key operational/environmental parameters that will be used shortly to postulate functional relationships between these parameters and metrics for HALE platform intelligence and elegance. 
Table 4. Functional Relationship Assessment

\begin{tabular}{|c|c|c|c|c|c|c|c|c|}
\hline Notional HALE Mission & $\begin{array}{l}\text { Planetary } \\
(\mathrm{F}=1) \text { or } \\
\text { Terrestrial } \\
(\mathrm{F}=0)\end{array}$ & $\begin{array}{l}\text { Duration, } \\
\text { T (Days) }\end{array}$ & $\begin{array}{l}\text { Alt. } \\
\text { (kft) }\end{array}$ & $\begin{array}{l}D_{I}^{*} \\
(\mathbf{1 - 1 0})\end{array}$ & $\begin{array}{l}D_{R}^{*} \\
(\mathbf{1 - 1 0})\end{array}$ & $\begin{array}{l}D_{I N}^{*} \\
(\mathbf{1 - 1 0})\end{array}$ & $\stackrel{\aleph}{\aleph}$ & $\begin{array}{l}\mathrm{i}^{*} \\
(1-10)\end{array}$ \\
\hline Telecom Relay Platform & 0 & 30 & 60 & 1 & 2 & 2 & 4 & 2 \\
\hline Storm Tracker & 0 & 4 & 40 & 3 & 7 & 3 & 4 & 4 \\
\hline $\begin{array}{l}\text { Border and Littoral Water } \\
\text { Patrol }^{22}\end{array}$ & 0 & 4 & 40 & 4 & 2 & 3 & 4 & 3 \\
\hline $\begin{array}{l}\text { Station-Keeping Science } \\
\text { Platform }\end{array}$ & 0 & 30 & 40 & 3 & 1 & 2 & 4 & 3 \\
\hline Long-Range Science Platform & 0 & 4 & 40 & 3 & 5 & 4 & 5 & 4 \\
\hline $\begin{array}{l}\text { Sensor-Network Aerial } \\
\text { Constellation }\end{array}$ & 0 & 4 & 25 & 4 & 3 & 7 & 5 & 4 \\
\hline Wildfire Surveyor & 0 & 1 & 25 & 3 & 3 & 2 & 3 & 3 \\
\hline \multicolumn{9}{|l|}{ Aerial Explorers } \\
\hline $\begin{array}{l}\text { - ARES-type prescribed flight } \\
\text { paths } 15,19\end{array}$ & 1 & 0.04 & 3.28 & 2 & 2 & 1 & 3 & 3 \\
\hline $\begin{array}{l}\text { - Search \& Find } \\
\text { Behaviors }\end{array}$ & 1 & 0.33 & 1.64 & 4 & 4 & 2 & 4 & 5 \\
\hline $\begin{array}{l}\text { - Surface Interactive - robotic } \\
\text { symbiotes }^{12}\end{array}$ & 1 & 30 & 0.66 & 6 & 6 & 7 & 5 & 7 \\
\hline $\begin{array}{l}- \text { Surface }^{-} \text {Interactive } \\
\text { VTOL }^{18}\end{array}$ & 1 & 90 & 0.033 & 7 & 8 & 8 & 5 & 8 \\
\hline
\end{tabular}

As can be expected, the Table 4 values are only approximate descriptions of a broad range of possible mission types. Resulting functional relationships have been derived on the basis of functional analysis using the Table 4 "data" - which in turn was derived using collective engineering judgment. Refer to the following:

$$
\iota^{*}=f\left(F, T, A l t, D_{I}, D_{R}, D_{I N}, \aleph\right)
$$

Or, more specifically

$$
\begin{array}{r}
l^{*} \approx a_{0} u(F-1)+a_{1}(1+u(\aleph-2)+u(\aleph-5))+a_{2} D_{I}^{*}+a_{3} D_{R}^{*} \\
+a_{4}\left(1-e^{-m_{1} D_{I N}^{*}}\right)+a_{5}\left(1-e^{-m_{2} / A l t}\right) \\
+a_{6} \frac{T}{T+1} e^{-m_{3} / T}
\end{array}
$$

Where the following constant values are suggested (so at to arrive at agreement with the Table 4 results): $\mathrm{a}_{0}=1, \mathrm{a}_{1}=$ $0.5, \mathrm{a}_{2}=0.25, \mathrm{a}_{3}=0.25, \mathrm{a}_{4}=0.5, \mathrm{a}_{5}=1$, and $\mathrm{a}_{6}=0.5 ; \mathrm{m}_{1}=0.5, \mathrm{~m}_{2}=1000$, and $\mathrm{m}_{3}=10$. Note that constants $\mathrm{m}_{2}$ and $\mathrm{m}_{3}$ are relatively large and are used to scale $\mathrm{T}$ and Alt. Figure 9a-f illustrates the incremental normalized intelligence metric trends with the key independent parameters. 

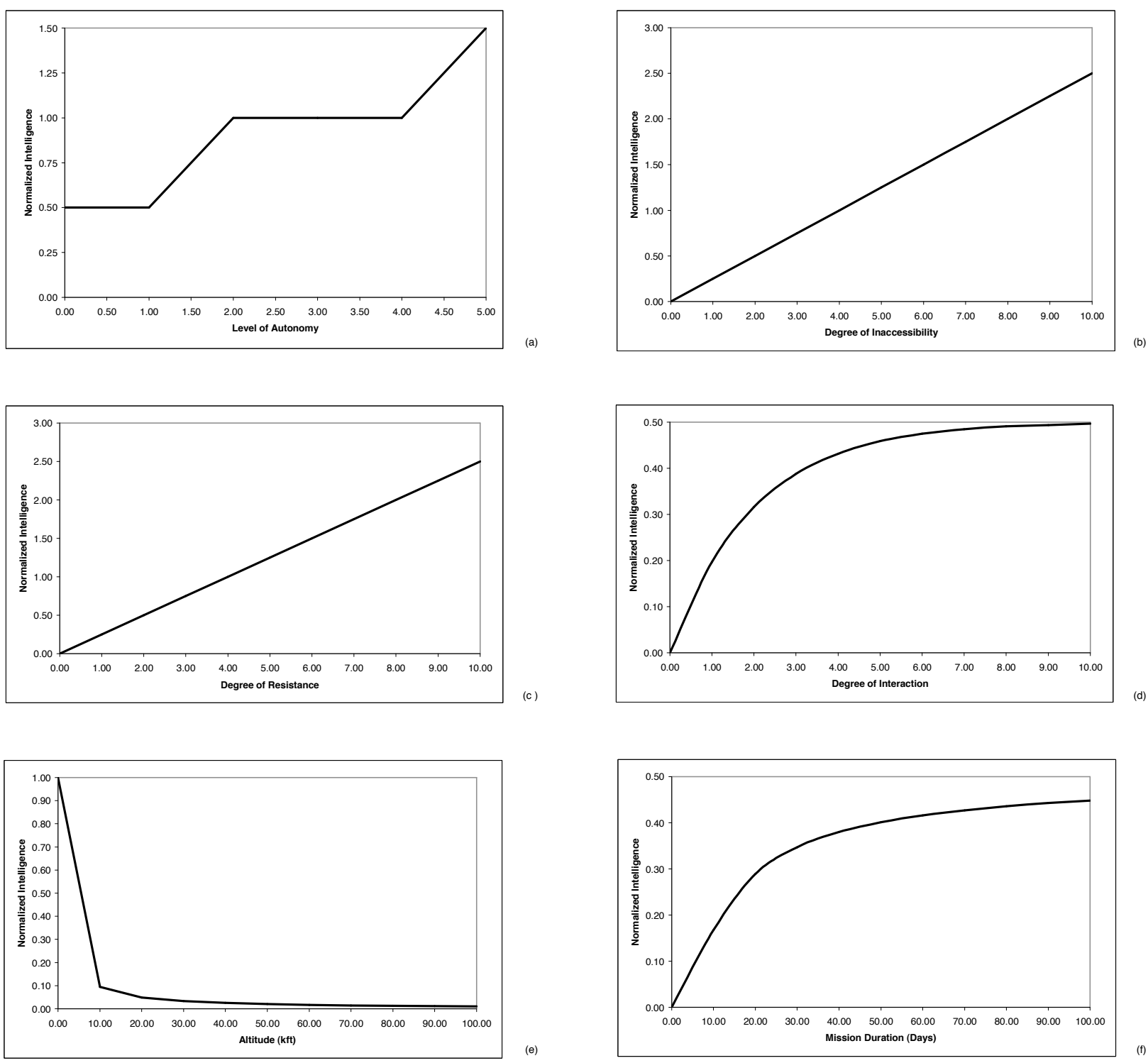

Figure 9a-f. Incremental Vehicle Normalized Intelligence Contribution from Key Mission Parameters: (a) LOA, (b) $D_{\mathrm{I}}$, (c) $\mathrm{D}_{\mathrm{R}}$, (d) $\mathrm{D}_{\mathrm{IN}}$, (e) cruise altitude, \& (f) mission duration

\section{E. Individual Autonomous System Technologies \& Achieving Autonomy Metrics \& Goals}

Relating the development progress and contribution of individual technologies, represented by the $\mathrm{j}^{\text {th }}$ array element $\mathbf{B}_{j}^{*}$, to the overall intelligence metric for autonomous aerial vehicles is performed as follows

$$
\mathbf{B}_{j}^{*}=\frac{\mathbf{W}_{j}^{*} \mathbf{B}_{j}+W_{0}^{*} \mathbf{I}_{j}^{*} S}{\mathbf{W}_{j}^{*}+W_{0}^{*}} \quad \text { for } \mathrm{j} \geq 1
$$

Where $\mathrm{S}$ is a normalized $(\mathrm{S} \leq 1)$ "mission success" metric derived from mission simulations incorporating the individual autonomous system technologies in specified set of vehicle/mission scenarios. Note that $\mathbf{W}_{0}^{*}$ and $\mathbf{W}_{j}^{*}$ 
comprise a set of weighting factor metric for relative weighting given to the two types of technology assessments embodied in Eq. 13. The weight $\mathbf{W}_{0}^{*}$ is given to the "objective" simulation-derived mission success technology assessment. The weight $\mathbf{W}_{j}^{*}$ is given to the technologist's "self-assessment" of the normalized technology readiness level (TRL) of the jth autonomous system technology implemented in the mission simulation, $\mathbf{B}_{j}$, or as otherwise denoted by

$$
B \equiv\left[\begin{array}{c}
\text { TRL of the 1st Technology divided by "9" } \\
\ldots \\
\text { TRL of the jth Technology divided by "9" } \\
\ldots
\end{array}\right]
$$

Note by definition that $W_{0}^{*}+\mathbf{W}_{j}^{*}=2$ must hold true for all technologies, i.e. all values of $\mathrm{j}$. The weights $\mathbf{W}_{j}^{*}$ are specified as follows, relying on the matrix $\mathbf{Q}$, which in turn is derived from the QFD-inspired tabular matrix shown in Fig. 10.

$$
\mathbf{W}_{j}^{*}=a \mathbf{I}_{j}^{*} \quad \text { and } \quad \mathbf{I}_{j}^{*}=u\left(10 \frac{\mathbf{W}_{j}}{W_{F}}+l^{*}-9\right)
$$

Where

$$
W_{F}=\max (\mathbf{W}) \quad \text { and } \quad \mathbf{W}_{j}=\sum_{i} \mathbf{Q}_{i, j}
$$

The constant a, Eq. 15a, is arbitrarily assigned to reflect the relative weight of $\mathbf{W}_{j}^{*}$ with respect to $\mathbf{W}_{0}^{*}$; a=1.0 is suggested. The array $\mathbf{W}$ can be thought of as denoting the relative importance of each individual technology, based upon the $\mathbf{Q}$ matrix input, as to contributing the overall goals of the project. This will be discussed further in the analysis and results section. Note that during the course of flight tests and/or mission simulations (embodying the autonomous system implementation), if an individual technology is not implemented then the "TRL" value of that technology is set to zero (irrespective of its previously demonstrated, but not implemented in the current simulation or flight test).

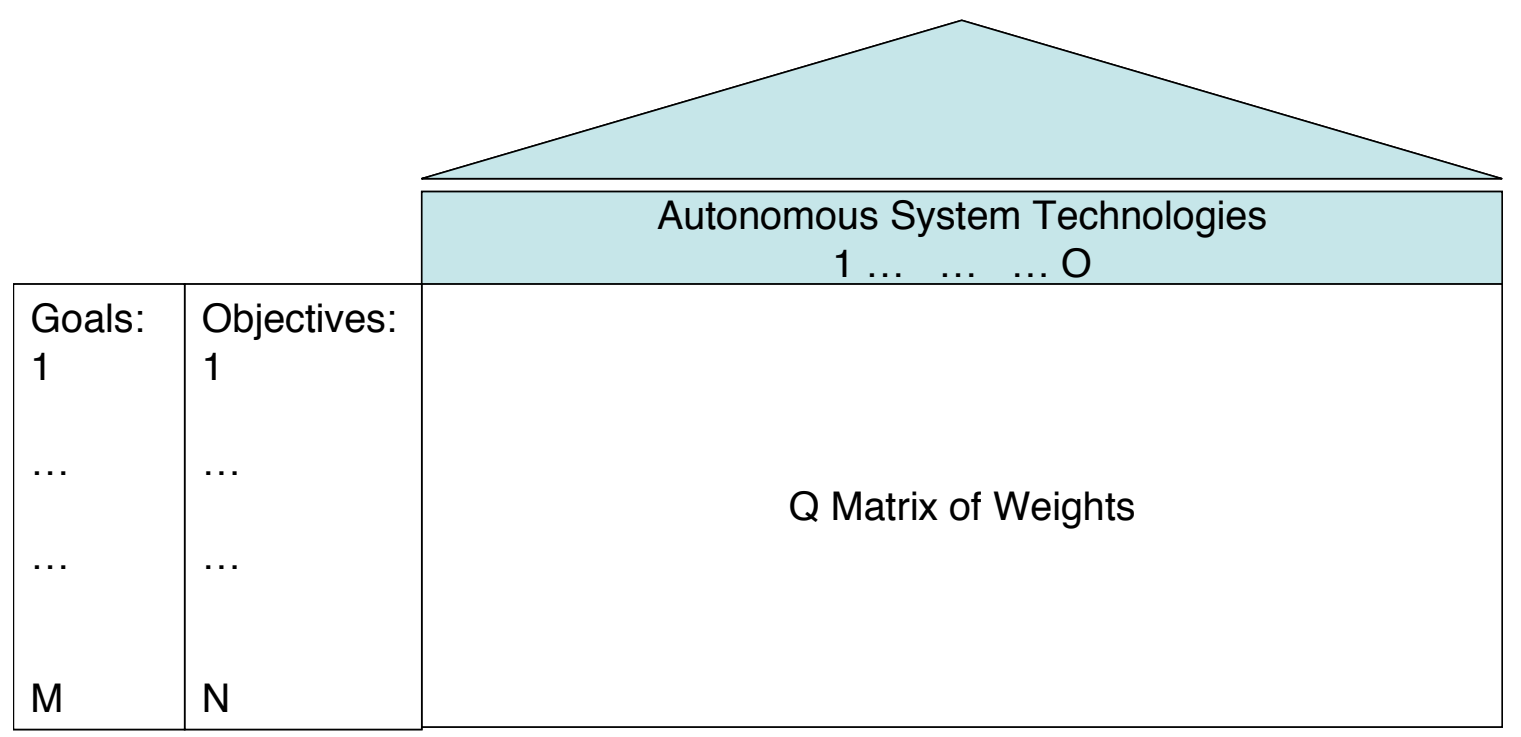

Figure 10a. General format of QFD-Inspired Tabular Matrix 


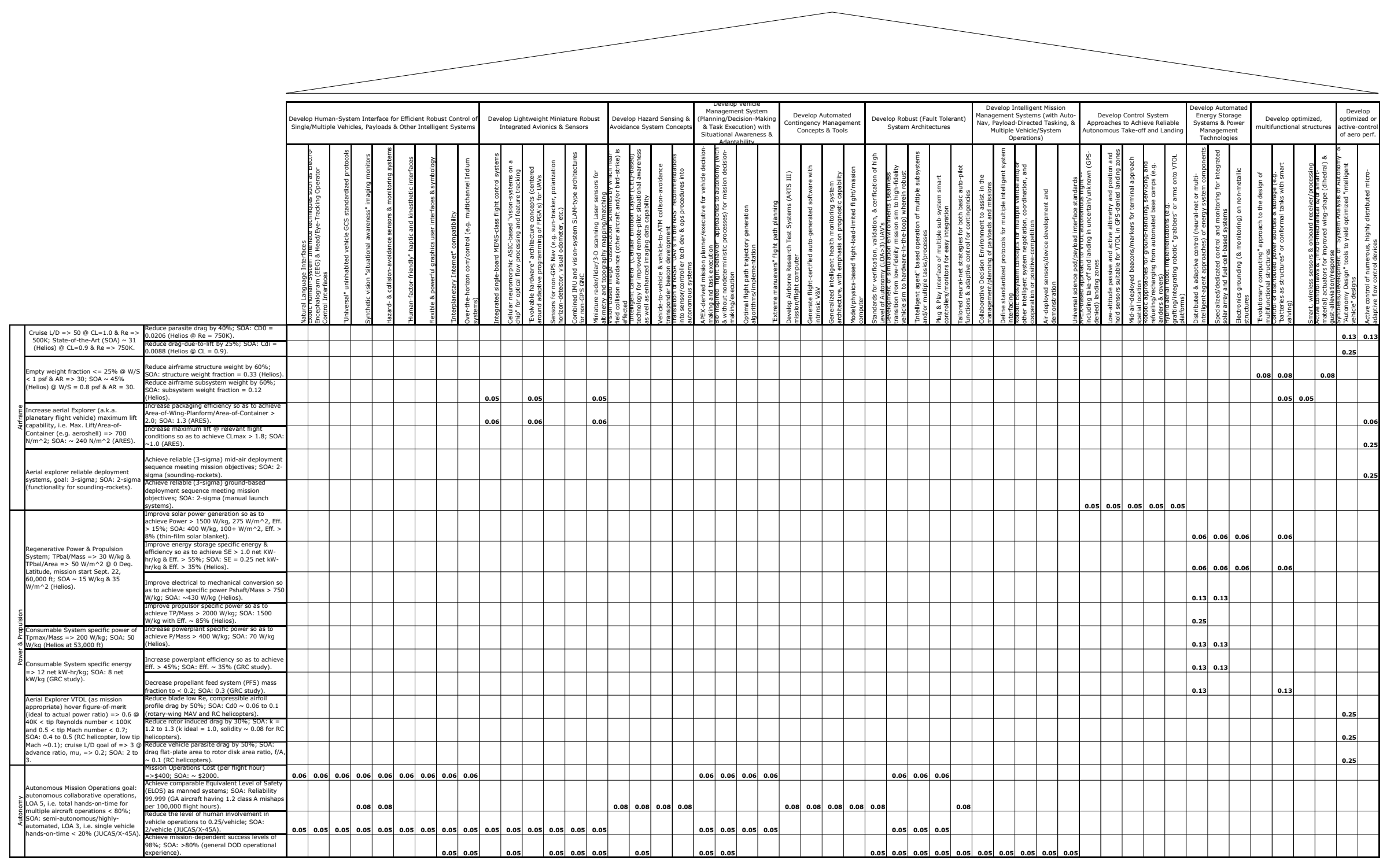

Figure 10b. A "House of Quality" QFD-Inspired Matrix for HALE UAV in terms of Autonomous System Capabilities 
Finally, the progress towards developing individual autonomous system technologies needs to be tracked against progress towards overall programmatic goals/objectives (in so far as affected by those same autonomous system technologies, and not other "extraneous" vehicle technologies). This is accomplished in the proposed analysis by the following relationship for "fractional anticipated contribution to goal" array, $\mathbf{C}_{i}^{*}$.

$$
\mathbf{C}_{i}^{*}=\mathbf{C}_{i} / \sum_{j} \mathbf{Q}_{i, j}
$$

Where

$$
\mathbf{C}=\mathbf{Q B}^{*}
$$

Note that by definition, for a given i'th row of the matrix $\mathbf{Q}$, the following holds true

$\sum_{j} \mathbf{Q}_{i, j} \leq 1$

It is appropriate to examine these notional vehicle/mission autonomous system capabilities in the context of a matrix inspired by Quality Function Deployment (QFD) "house of quality" matrix representation ${ }^{3-6}$ - refer to Fig. 10. The contents of this matrix naturally flow from the goals, objectives, technical challenges, and approaches (as derived by the well-known "GOTChA" process) developed and vetted by the VSP HALE Sector with appropriate review from NASA independent reviewers, industry and academia. ${ }^{7}$ Note that the matrix columns represent the definition of a detailed technology capability set -- as affected (and only affected) by autonomous system technology -- consistent and supportive with respect to the HALE-sector-team-identified technical approaches.

Note that the initial weighting factors, $\mathbf{Q}_{\mathrm{i}, \mathrm{j}}$, used in the Fig. 10 QFD-inspired matrix can be determined as per Eq. 19. This initial weighting factor scheme assumes that contributing autonomous system technologies all uniformly/equally contribute to the i'th Goal with the nominal partitioning between enabling $(A=1)$ and contributing technologies $(\mathrm{A}=0.25)$.

$$
\mathbf{Q}_{i, j}=\frac{A}{\text { Number of Contributing Autonomous System Technologies, including j' th technology, to ith Goal }}
$$

Subsequent iterations on the Fig. 10 weighting factors can be adjusted to reflect sensitivity analysis results and/or mission simulations that show that autonomous system technologies do not uniformly contribute to the goals. Additionally, the weighting factors can also reflect resource/funding issues that may not fully stem from engineering considerations alone (i.e. not all promising technologies may be funded at the required levels, or funded at all, to achieve the anticipated contributions to the technology goals).

\section{F. Other Considerations in UAV Autonomy}

Finally what is also required to help evaluate UAV autonomous system capabilities is essentially a "Turing Test" ${ }^{\text {" }}$ for autonomous aerial vehicles. Such testing would have to be conducted by means of extensive mission simulations of the vehicle under the guidance of its autonomous system software. Such autonomous vehicle mission simulations would also have to be benchmarked against missions "flown" with pilots/human-operators in the loop. In turn, scoring criteria for such testing could be based upon 1. overall mission success metrics (defined as in Table 3) and 2. by "handling quality" metrics similar to the well-known Cooper-Harper ${ }^{10}$ pilot ratings used for manned 
aircraft. Autonomous aerial vehicles would be considered to have successfully passed this "UAV Turing Test" if the aggregate mission success and handling qualities for the autonomous aerial vehicle matched or exceeded the equivalent metrics for missions conducted with pilots/human-operators in the loop.

Table 5. Notional "UAV Turing Test" Comparison

\begin{tabular}{|l|l|l|}
\hline \multicolumn{1}{|c|}{ Flight Phases } & Mission "X"-Autonomous & Mission "X" - "Piloted" \\
\hline $\begin{array}{l}\text { Take-off (with x\% probability - Gaussian } \\
\text { distribution - of runway abort) }\end{array}$ & & \\
\hline$\ldots$ & & \\
\hline $\begin{array}{l}\text { Navigating and flying waypoint-to-waypoint } \\
\text { trajectories within prescribed precision }\end{array} \ldots$ & & \\
\hline$\ldots$ & & \\
\hline $\begin{array}{l}\text { Landing (with z\% probability of final } \\
\text { approach abort) }\end{array}$ & & \\
\hline
\end{tabular}

Alternatively, a third-party knowledgeable observer could provide the "UAV Turing Test" ratings of whether a vehicle is autonomous or "piloted" (i.e. "check" the boxes in Table 5). This observer/rater would also have the additional role of being able to override the scripted mission scenario and instigate failure modes and change of flight profile/plans. If the majority of tasks are rated as "piloted" by the observer, when in reality the vehicle/simulation is fully- or semi- autonomously controlled, then the vehicle/simulation "passes" the "UAV Turing Test." In this regards, this "UAV Turing Test" approach is more consistent with Turing's original "imitation game" proposal. ${ }^{9}$

Finally, as was noted earlier, system analysis of autonomous systems should consider and address first-order concerns regarding unique UAV operational hazards in order to examine reasonable trades between the vehicle LOA, intelligence, and elegance. Therefore, the appropriate questions are as follows. What then are the unique consequences of the autonomous system failure, versus human operator error, for the UAV, the mission, and collateral human/property damage? A corollary to this question is, are there unique hazards for autonomous HALE UAVs versus (remote-piloted) human operation, or is it merely a question of relative respective probabilities of occurrence for a commons set of hazards? The short answer is that both occur - there are some unique hazards as well as many other hazards where it is only a matter of relative probability between a hazard seen by a piloted (human-occupied) versus autonomous aerial vehicle. This issue is further complicated by the fact that many manned aircraft have, or will have, highly automated sub-systems onboard them, resulting in a grey area as to what is a "unique UAV hazard," at least as far as autonomous systems technologies are concerned. Table 6 is a representative subset of the operational hazards associated with manned aircraft versus uninhabited aerial vehicles, as influenced by autonomous system technologies. 
Table 6. Uniquely Human versus Autonomous System Operational Hazards

\begin{tabular}{|c|c|c|c|}
\hline Category & Probability & Hazard & Hazard Control(s) \\
\hline \multicolumn{4}{|c|}{ Uniquely Human Hazards -- } \\
\hline $\mathrm{I}$ & $\begin{array}{c}\text { See note } \\
\text { below }\end{array}$ & $\begin{array}{l}\text { Errors in judgment due to human } \\
\text { (pilot, engineer/tech support } \\
\text { staff, payload specialists, etc.) } \\
\text { fatigue or work overload. }\end{array}$ & $\begin{array}{l}\text { 1. Implement ergonomic human-factor friendly } \\
\text { interfaces and control and decision-making tools } \\
\text { 2. Implement balanced portfolio of autonomous system } \\
\text { technologies on the vehicle and in ground-control }\end{array}$ \\
\hline II & * & $\begin{array}{l}\text { Mission failure, or reduced } \\
\text { operational value (e.g. missed } \\
\text { opportunities), as a consequence } \\
\text { of inadequate response time for } \\
\text { human mission planners to } \\
\text { discuss/achieve consensus. }\end{array}$ & $\begin{array}{l}\text { 1. Enhance/augment human mission planners with } \\
\text { intelligent mission management tools } \\
\text { 2. Implement internet-like data/information networking } \\
\text { to maximize efficiency of the mission planner decision- } \\
\text { making process (making sure all vested interested are } \\
\text { represented in real-time despite geographic distribution) }\end{array}$ \\
\hline I & $*$ & $\begin{array}{l}\text { Mission/vehicle loss, or reduced } \\
\text { operational value, due to } \\
\text { inadequate reaction time for the } \\
\text { pilot to interpret advanced (non- } \\
\text { visual) sensor suite input to } \\
\text { maintain adequate vehicle } \\
\text { control }\end{array}$ & $\begin{array}{l}\text { 1. A key justification for the use of autonomous UAVs } \\
\text { for high-risk military or public missions } \\
\text { 2. "Pilot-in-the-loop" simulations examining sensor } \\
\text { fusion and display(s) during relevant mission scenarios } \\
\text { including adverse weather conditions (e.g. low-visibility) } \\
\text { and/or extreme operating conditions (e.g. high-speed, } \\
\text { low-altitude flight). }\end{array}$ \\
\hline II & $\begin{array}{c}\text { See note } \\
\text { below }^{\dagger}\end{array}$ & $\begin{array}{l}\text { Mission abort/failure under } \\
\text { special circumstances where } \\
\text { vehicle ( } \& \text { occupants) can not be } \\
\text { treated (as needed) as } \\
\text { expendable }\end{array}$ & $\begin{array}{l}\text { 1. Another key justification for use of UAVs in high-risk } \\
\text { military or public good missions } \\
\text { 2. Costly reliance on other assets (e.g. ground troops, } \\
\text { artillery, and air-suppression for military missions) to } \\
\text { reduce aircraft and aircrew risk down to acceptable levels }\end{array}$ \\
\hline$\ldots$ & $\ldots$ & & \\
\hline \multicolumn{4}{|c|}{ Unique Autonomous System Hazards -- } \\
\hline $\mathrm{I}$ & $*$ & $\begin{array}{l}\text { Vehicle, or mission loss, due to } \\
\text { improper/inadequate software } \\
\text { programming \& testing }\end{array}$ & $\begin{array}{l}\text { 1. Adoption of formal software validation and } \\
\text { verification processes } \\
\text { 2. Rigorous "hardware-in-the-loop" ground-testing } \\
\text { 3. Extensive mission simulations (especially when } \\
\text { mission includes flight in unknown/uncertain } \\
\text { environments and/or non-deterministic autonomous } \\
\text { decision-making processes are employed) }\end{array}$ \\
\hline II & $\dagger$ & $\begin{array}{l}\text { Improper execution of flight } \\
\text { behaviors/tasks as a consequence } \\
\text { of using nondeterministic } \\
\text { (stochastic or heuristic) vehicle } \\
\text { decision-making processes }\end{array}$ & $\begin{array}{l}\text { 1. Use non-deterministic processes (hardware/software) } \\
\text { when only absolutely essential to assure mission success } \\
\text { 2. Tightly/deterministically constrain the limits of action } \\
\text { (task execution) that can be effected by non-deterministic } \\
\text { processes (i.e. "idiot-proof" the actions/controls that are } \\
\text { commanded/tasked by the nondeterministic processor) }\end{array}$ \\
\hline II & $\dagger$ & $\begin{array}{l}\text { Improper implementation of } \\
\text { adaptive flight control } \\
\text { techniques (with either micro- } \\
\text { flow control actuators or } \\
\text { conventional control surfaces), } \\
\text { especially under highly degraded } \\
\text { vehicle operating conditions }\end{array}$ & $\begin{array}{l}\text { 1. Extensive ground-test and wind-tunnel testing; } \\
\text { coupled with flight test envelope expansion that carefully } \\
\text { examines adaptive flight control techniques/actuators - } \\
\text { including simulated vehicle/actuator failures and } \\
\text { performance degradation } \\
\text { 2. Incorporation of high (\& costly) risk margins for } \\
\text { aircraft hardware/systems as a contingency to restrained } \\
\text { use of adaptive flight control techniques }\end{array}$ \\
\hline $\mathrm{I}$ & $*$ & $\begin{array}{l}\text { Flight load limit excursions, or } \\
\text { unanticipated system failures, } \\
\text { because of an improperly } \\
\text { functioning intelligent vehicle } \\
\text { system management system. } \\
\end{array}$ & $\begin{array}{l}\text { 1. Adoption of formal software validation and } \\
\text { verification processes } \\
\text { 2. Rigorous "hardware-in-the-loop" ground testing of } \\
\text { intelligent vehicle system management systems (e.g. load } \\
\text { limiting avionics, health monitoring and prognostics). }\end{array}$ \\
\hline & & & \\
\hline
\end{tabular}


Note, the following are definitions of the above severity categories and hazard probabilities: Category I. "catastrophic," II. "critical," III. "marginal," and IV. "safe." (or, rather, let C= $(5-1)=4$, $(5-2)=3,(5-3)=2$, and $(5-4)=1)$; Probability levels of "probable," "remote," "improbable," and "highly improbable" (or a value of $\mathrm{P}$ is assigned such that it falls within the discrete ranges of $0.1 \leq \mathrm{P} \leq 1.0,0.01 \leq \mathrm{P} \leq 0.1,0.001 \leq \mathrm{P} \leq 0.01$, and $0 \leq \mathrm{P} \leq 0.001$ - which is more consistent with an experimental flight test program and not production aircraft). Further, note that: "approximate probabilities can be assigned on the basis of existing (though perhaps with limited operational experience) manned and UAV aircraft, and these probabilities can only be assessed as developmental experience with individual autonomous system technologies (for a given vehicletype and mission) are gained.

The Table 6 hazards are at a fairly high level. Ideally, each of the individual technologies identified in the Fig. 10 tabular matrix should have its own one or more specific hazards associated with it. The results of such an expanded detailed technology/hazard analysis can be recast to the following matrix form for subsequent analysis.

$$
\mathbf{H}=\left[\begin{array}{ccccc} 
& \text { 1st Hazard } & \ldots & \text { jth Hazard } & \ldots \\
\text { 1st Technology } & C \cdot P & \ldots & \ldots & \ldots \\
\ldots & \ldots & \ldots & \ldots & \ldots \\
\text { ith Technology } & \ldots & \ldots & C \cdot P & \ldots \\
\ldots & \ldots & \ldots & \ldots & \ldots
\end{array} \mid\right.
$$

Given the above, the individual technology hazard rating, accounting for technology maturation/readiness, is given by

$$
\mathbf{H}_{i}^{*}=\sum_{j} \mathbf{H}_{i, j} / \mathbf{B}_{i}^{*}
$$

Where the individual developmental progress made towards an (i'th) autonomous system technology, $\mathbf{B}_{i}^{*}$, is given, as earlier, by Eq. 13. The smaller the value of $\mathbf{H}_{i}^{*}$, then the smaller the overall hazard for a given autonomous system technology, at its current demonstrable (at least in terms of simulation, that is) technology readiness/maturation.

Finally, to complete this discussion of vehicle/mission hazards, it is important to note that the cost/risk trade between using manned aircraft versus UAVs for identical/similar missions is an important area of investigation but outside the scope of this paper. Such cost/risk trades inevitably have to address cost metrics related to the potential loss of manned aircraft (with attendant loss of crew and passengers) which, in turn, would need to address both "actual" versus "perceived" costs and benefits. These types of trades studies are really only applicable for military missions or high-risk, public-good, life-saving disaster-relief or other emergency missions where risk to the vehicle (and crew if applicable) must be traded against the "higher good" of rescuing fallen comrades or saving lives. And yet, UAVs may find their greatest utility under just these circumstances. As such, future system analysis work should be devoted to examining these types of issues. 


\section{Analysis and Preliminary Results}

The above outlined methodology for incorporating autonomous system technology considerations into aerial vehicle system analyses is very conjectural at this current stage of development. Validation of key assumptions and functional trends clearly needs to be performed as a next step.

The HALE technologies being developed by the NASA VSP are focused on enabling new mission capabilities. A mission level perspective is necessary to truly capture the importance and impact of these technologies. Short of conducting actual mission demonstrations, the best way to analyze the role of these new autonomous systems technologies in contributing to mission success is through mission simulations. Mission simulation capability is especially important in the case of autonomous systems technologies where it is not the traditional aircraft performance metrics (speed, range, endurance, etc.) that are impacted but mission level performance. Simulation modeling needs to be developed to assess the performance of HALE and PFV vehicles and technologies in "real world" application so as to both demonstrate the overall mission capabilities and track the benefits of technologies under development.

Some initial insights into the optimum level of vehicle autonomy and intelligence required for a particular HALE UAV mission/application can now be made, given the work presented so far. As noted earlier, whatever attempt to optimize vehicle performance in the context of vehicle autonomy and intelligence has to also allow for acceptable levels of success and risk while at the same time keeping development and implementation costs to a minimum. Figures 11 and 12 illustrate the general return on investment trends for autonomous aerial vehicles performing commercial mission applications. The MROI trends are shown as a function of mission duration and whether or not mission success is fixed-rate revenue (as a function of time) or fixed price per mission. Commercial HALE UAV "mission return on investment" will always be related ultimately to revenue and dollars. MROI, in this case, is relatively easy to interpret. The MROI concept is somewhat harder to interpret when the return is not in terms of revenue but scientific information/opportunities.

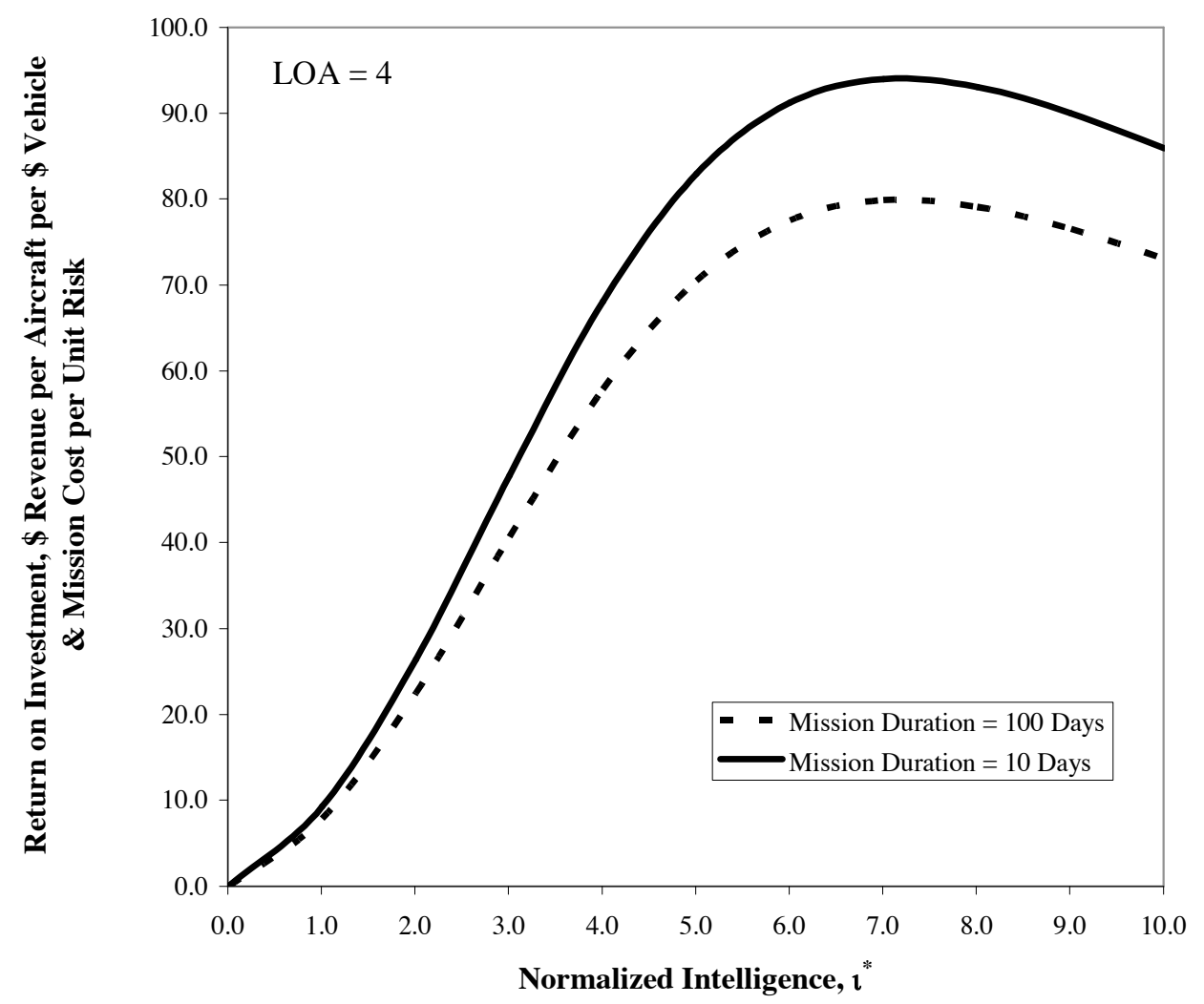

Figure 11. Return on Investment Trend as a function of Mission Duration (without cost penalty for increased launch/recovery frequency for shorter duration missions \& LOA = 4) 
One of the key observations to note in Fig. 11 is that there is an optimum peak in MROI with respect to the vehicle normalized intelligence metric; this is driven by the associated increase in risk and cost in having too much intelligence unnecessarily built into the vehicle to accomplish its given mission. The MROI trend results (accounting for risk as well as cost) for Fig. 11 do not incorporate a cost penalty for increased launch/recovery frequency for shorter duration missions. As such the Fig. 11 results show the shorter-duration aircraft (with more sorties) having higher MROI than the longer-duration aerial vehicle; this is direct consequence of the anticipated higher development costs and risks (associated with decreased reliability over longer time) for longer-duration vehicles. The MROI trend for the shorter-duration aircraft should shift downward somewhat when the cost penalty for launch/recovery frequency is accounted for.

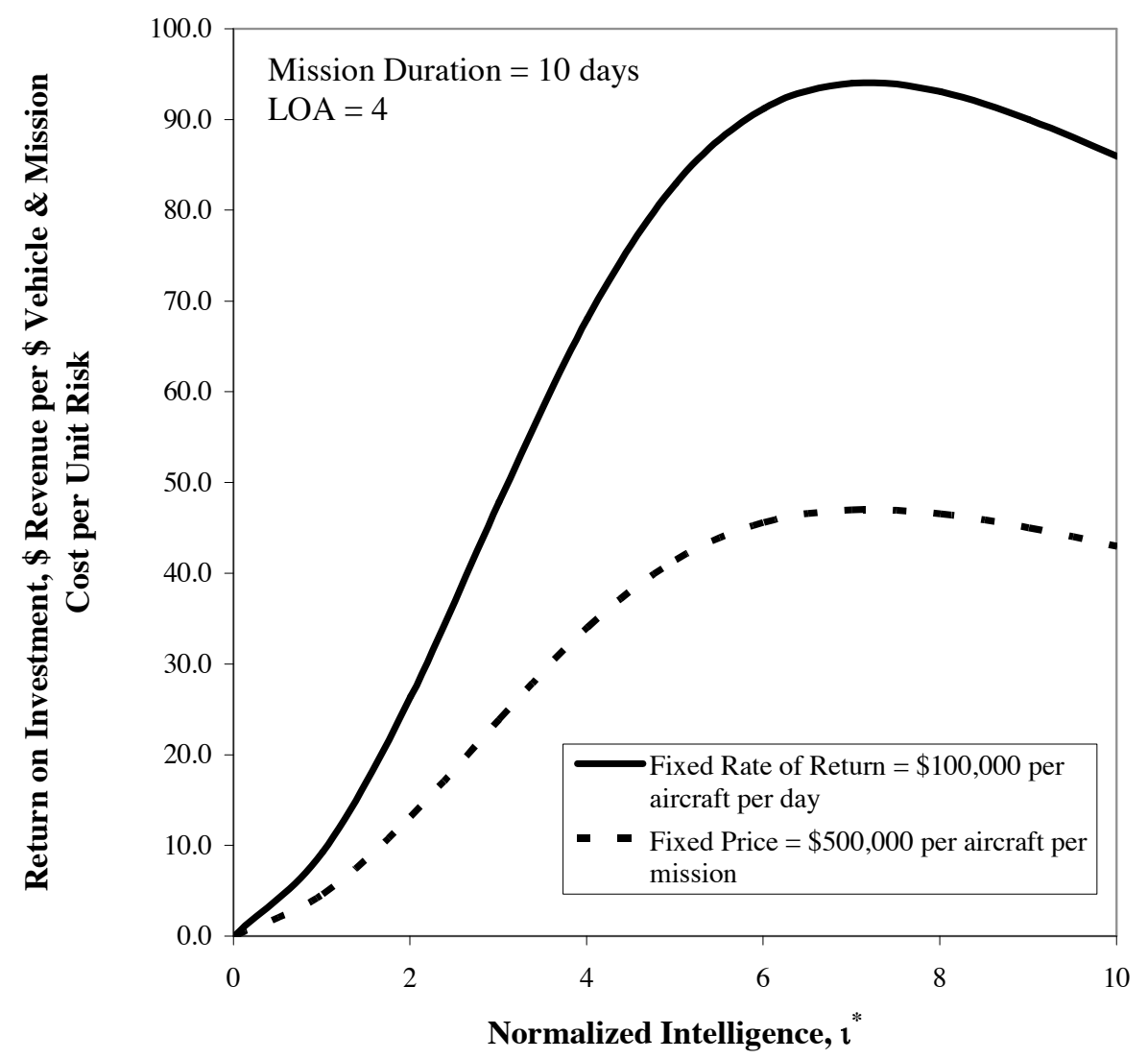

Figure 12. Mission Return on Investment Trends: Mission Success is directly proportional to (a) Mission Duration and (b) Fixed Mission Revenue (mission duration = 10 Days and LOA = 4)

Figure 12 illustrates the influence of mission success (and its overall functionality) on MROI -- in this case in the context of fixed-rate revenue which is dependent on mission duration and a fixed-price per mission revenue. In this particular case, Fig. 12, the fixed-price per mission charged is too low and is not competitive with respect to fixedrate per day pricing. The decision to pursue fixed-price versus fixed-rate pricing for commercial HALE UAV missions will be strongly influenced by the risk assumption for successfully sustaining over the complete planned duration of the mission.

Ultimately the cost associated with "autonomous system technology" development and implementation is only cost-effective in the context that reductions in operational staffing costs and maintenance manpower costs are sufficient to offset the increased vehicle development costs attributable to vehicle autonomy. present cost estimate trends for HALE UAV missions.

Figure 13 and 14 


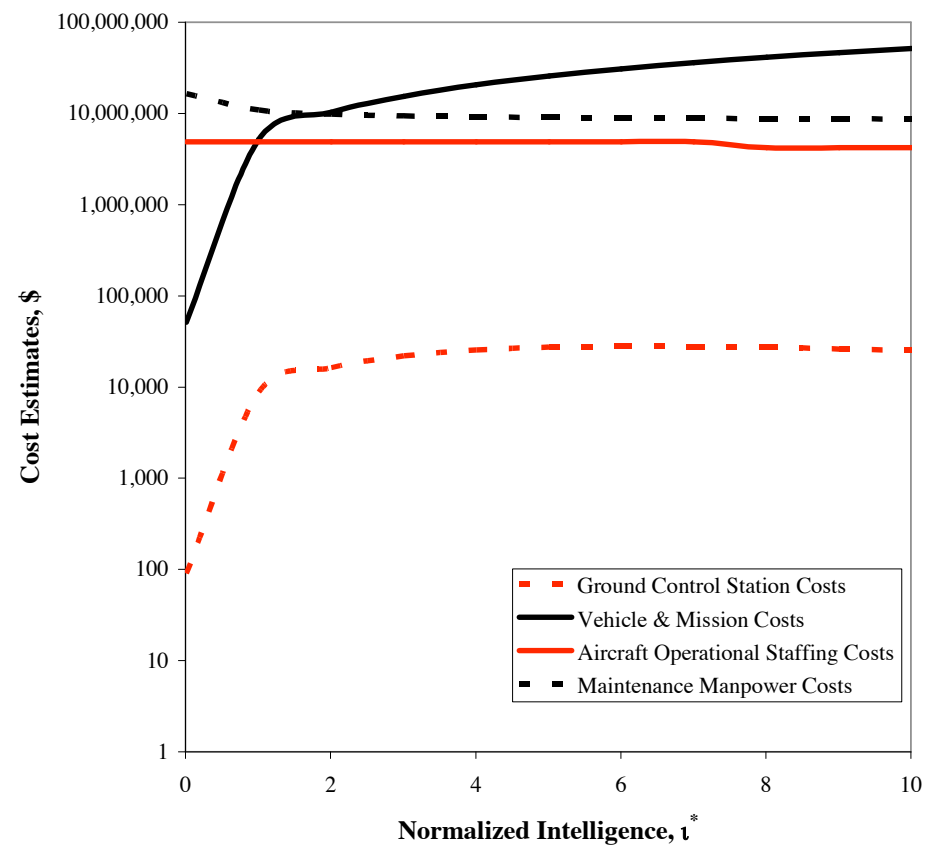

Figure 13. Cost Trend Estimates (LOA=4, Elegance=5, Aircraft Projected Life $=10$ years, and Aircraft Fractional Usage $=0.66$ )

Figure 13 presents the incremental costs associated for aircraft and mission, the ground control station (GCS), the operational staffing costs (in lieu of manned aircraft crew costs), and aircraft maintenance manpower. Next to the vehicle costs, maintenance manpower costs dominate - followed by operational staffing and GCS costs. Longer duration aircraft will create significant technical challenges to achieve the necessary reliability levels; achieving such reliability will dictate new autonomous system technologies with nontrivial development costs.

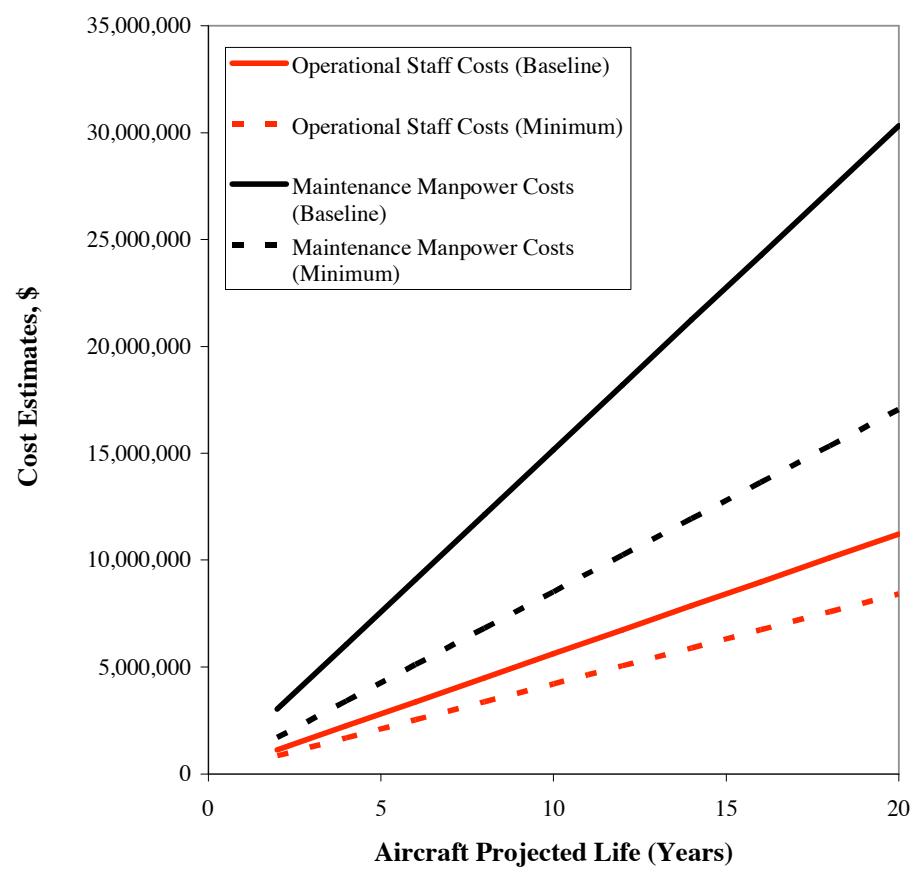

Figure 14. Operational Staff and Maintenance Manpower Cost Trends as a function of Aircraft Projected Life (baseline trends: $\imath^{*}=\varepsilon * 1$; minimum trends: $\imath^{*}=\varepsilon^{*}=10$ ) 
Figure 14 presents the cumulative operational staffing and maintenance manpower cost trends as a function of aircraft life. The difference between the "baseline" and "minimum" cost trends represents the potential cost savings for implementing pertinent autonomous system technologies.

What are the specific attributes of an autonomous system implementation essential for a given mission/application and aerial vehicle in order to maximize mission success? The results in Figs. 15-18 are drawn from, and are therefore consistent with, the numeric data contained within the QFD-inspired tabular matrix, $\mathbf{Q}$, shown in Fig. 10, given Eq. 19. The resulting distribution of Fig. 15 is a consequence of both the usage of uniform weighting of technologies contributing to an individual goal, as well as relative scaling of "enabling" versus “contributing” technologies within $\mathbf{Q}$.

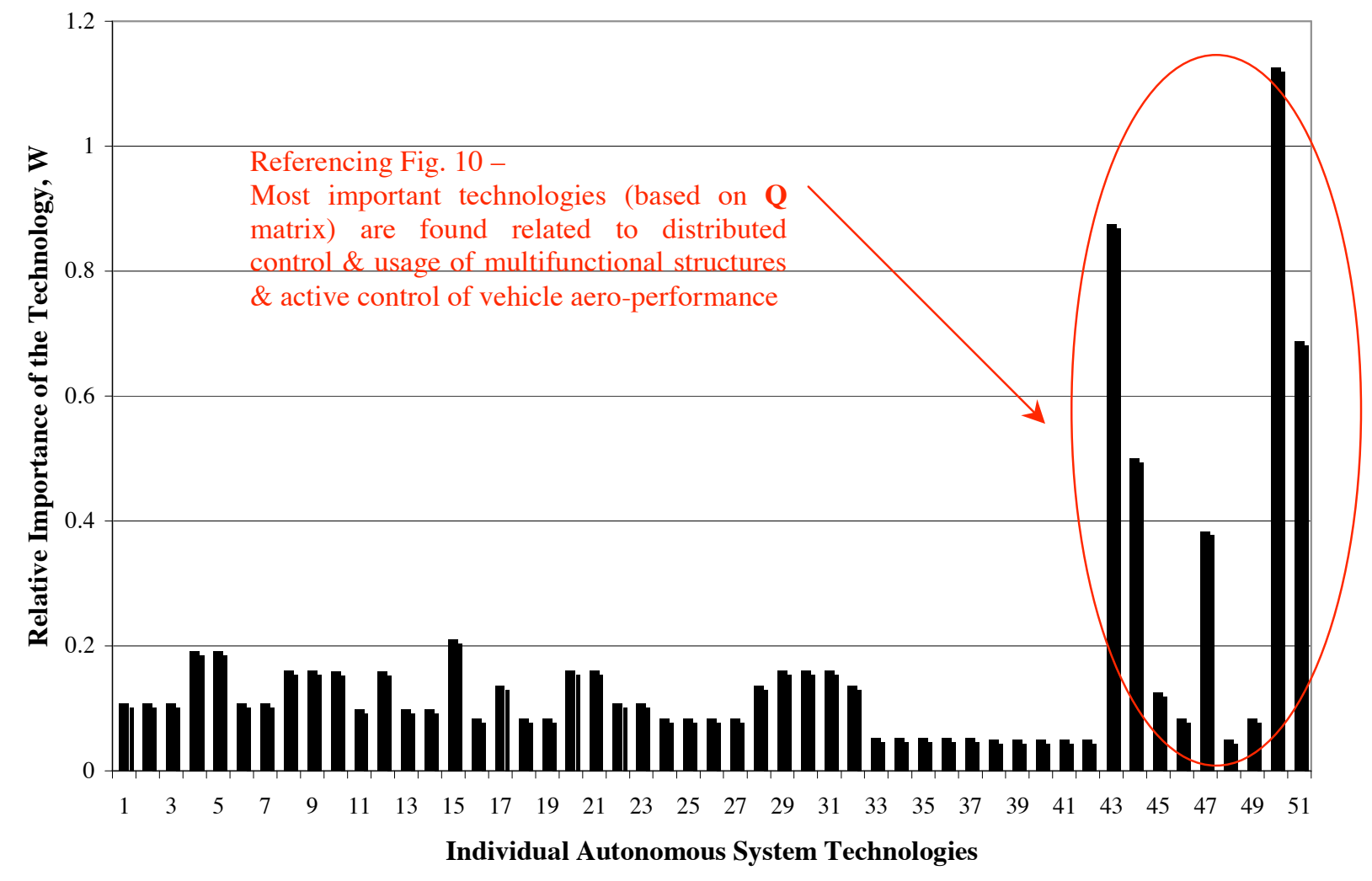

Figure 15. Prescribed relative importance of individual autonomous technologies

Given the uniform weighting used in the Fig. 10 tabular matrix, the most important (relatively speaking) are the technologies associated with the development and control of optimized multifunctional structures, and optimized and/or active-control strategies for vehicle aero-performance. Given the $\mathbf{Q}$ matrix derived from Fig. 10, the (number of funded) technology portfolio - as a function of the vehicle normalized intelligence metric -- is shown in Fig. 16. A more monotonic trend is desirable from a technology portfolio perspective - versus the near-exponential trend seen in Fig. 16. This will, in turn, dictate a future revisiting of the imposed uniform weighting in the $\mathbf{Q}$ matrix. 


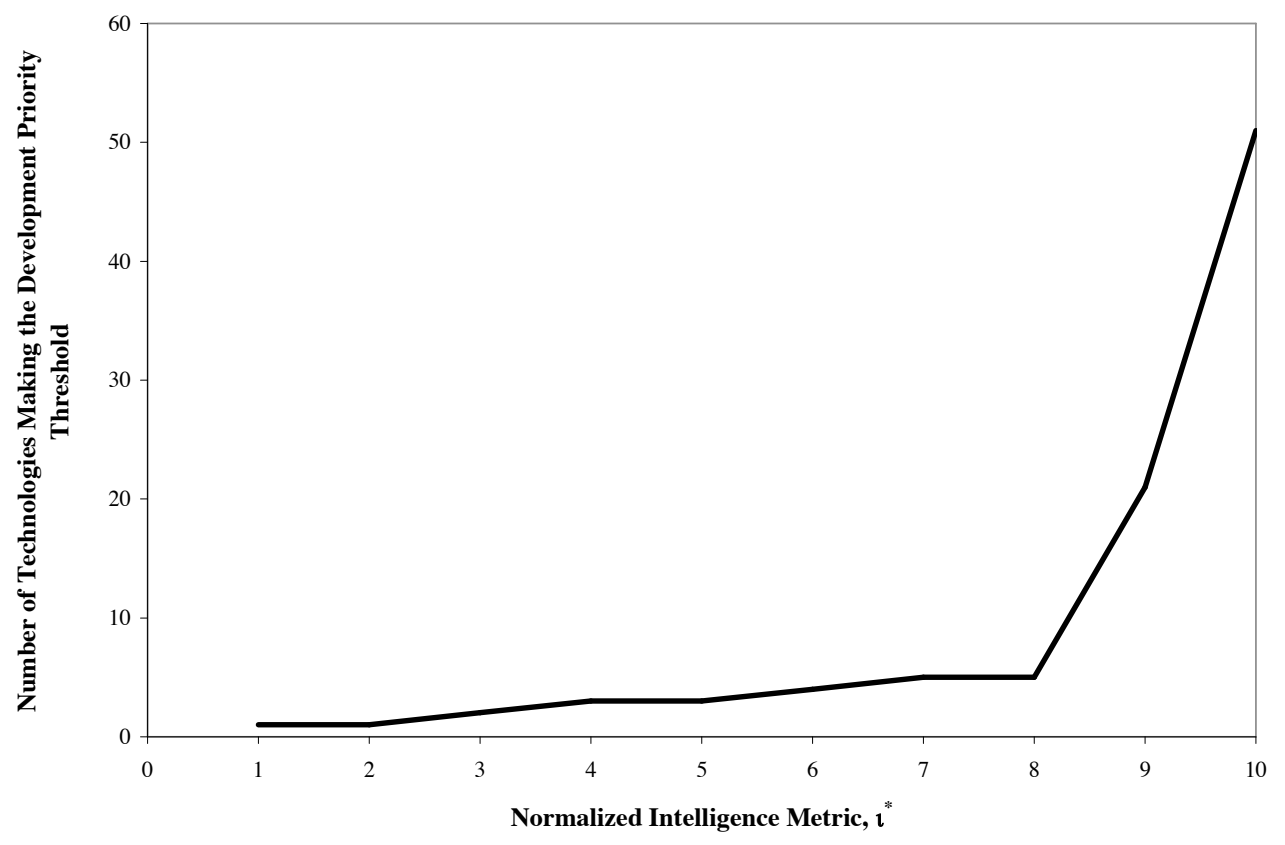

Figure 16. Portfolio assessment of technologies as a function of normalized intelligence metric target

Given an autonomous system technology portfolio assessment such as summarized in Figs. 15-16, running assessments can be made (based on concurrent mission simulation results) as to individual technology's anticipated fractional contribution to the goals (or more correctly the objectives intrinsic to the goals). Figures 17 and 18 show notional results for such a fractional contribution to goals assessment for two levels of self- and objective- estimates of individual technology progress. Figure 17 shows the progress made on an initial portfolio of high-priority technologies towards the vehicle/mission goals given a relatively low TRL and mission success metrics from early technology development efforts and mission simulation results. In Fig. 17 there are clear examples of where goals are not being met at the current normalized intelligence metric design target and the current self- and objective assessments of technology readiness/progress.

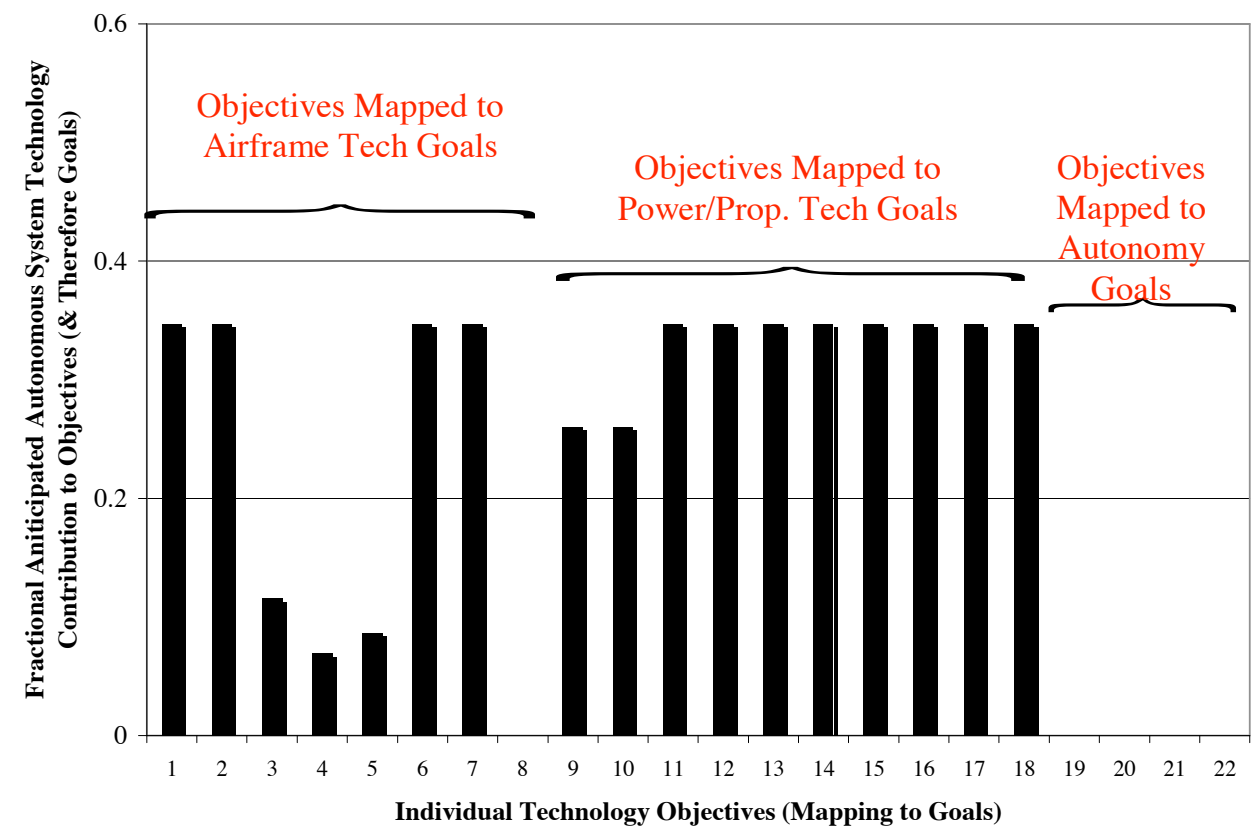

Figure 17. Progress towards objectives and goals (uniform technology self-assessment of TRL=4, mission simulation measured normalized mission success of $S=0.25$, and normalized intelligence metric target of $\imath^{*}=7$ ) 
Figure 18 illustrates a fractional contribution to goal assessment based on a notionally somewhat larger (in terms of a higher-priority portfolio) and more mature set of autonomous system technologies (from the Fig. $10 \mathbf{Q}$ matrix). In this example, goals are being more uniformly and consistently met. There are still, though, clear examples of where improved technological progress could be achieved relevant to the goals.

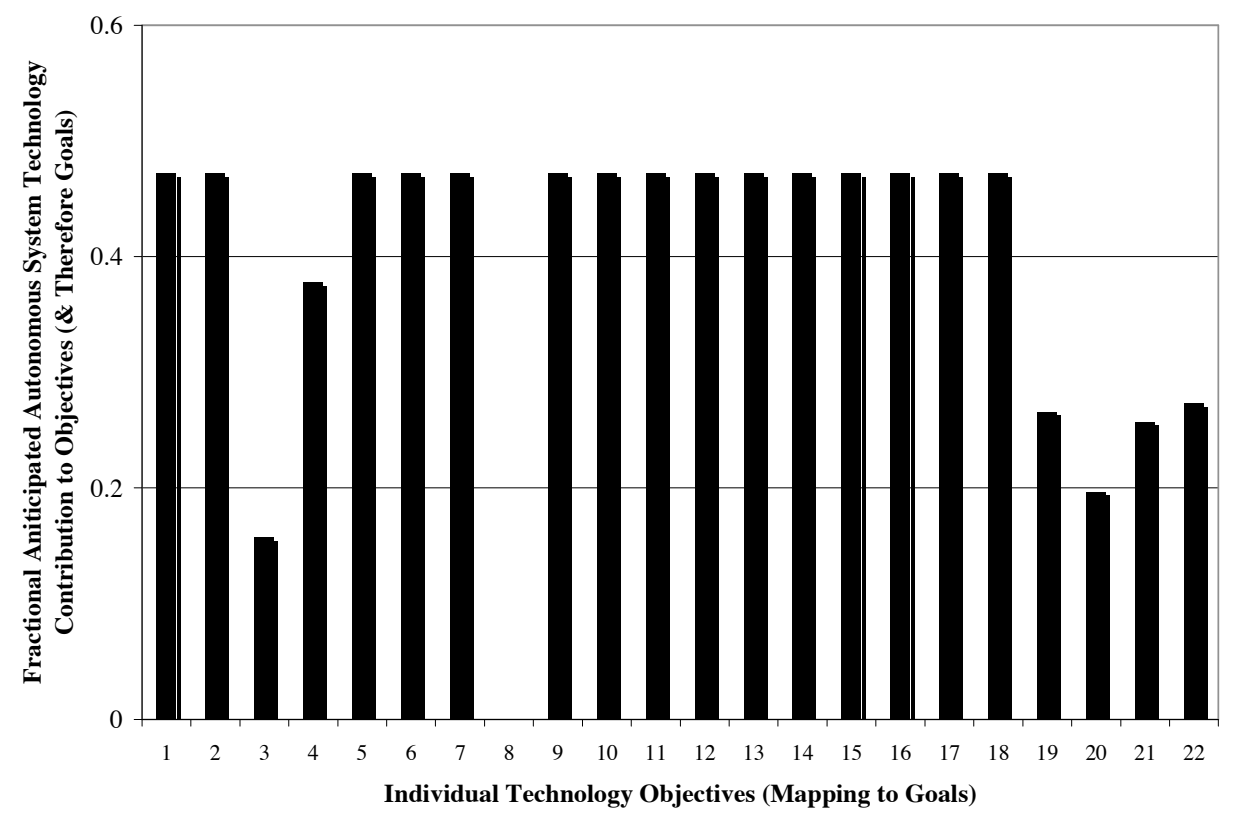

Figure 18. Progress towards objectives and goals (uniform technology self-assessment of TRL=4, mission simulation measured normalized mission success of $S=0.5$, and current normalized intelligence metric target of ${ }^{*}=9$ )

This concludes a very brief summary of the type of system analysis that can be performed in support of autonomous system trade studies for HALE UAV platforms. Considerably more work remains to be performed particularly in terms of validation and detailed mission assessments. This work will hopefully be recognized as an important first step in a new sub-domain of system analysis.

\section{Concluding Remarks}

The first step in solving a problem is to pose the right questions to ask and to investigate. A set of such questions has been posed in this paper for preliminary investigations into the impact of autonomous system technology on uninhabited aerial vehicles and HALE missions in particular. Additionally, a preliminary methodology for system analysis incorporating/considering autonomous system technology issues into the study of overall aerial vehicle capabilities and mission requirements has been outlined. In order to perform this system analysis it was critical to define autonomy metrics that were both quantifiable and practical. Additionally, first order functional relationships were proposed that related these autonomy metrics to vehicle characteristics and mission requirements. Finally, the contribution of individual autonomous system technologies (of which a large set were identified) were related in both a conceptual as well a quantitative sense to high-level programmatic goals, mission cost, risk, and return on investment criteria. All of this work is still fairly conjectural at this stage, though. Considerable work remains in order to arrive at a validated set of system analysis tools for UAVs and other automated and intelligent systems. 


\section{Acknowledgments}

The programmatic support of the NASA Vehicle Systems Program (VSP) is gratefully acknowledged in the performance of this work. Additionally, the programmatic contribution of our colleague Mr. Lawrence Camacho, Dryden Flight Research Center, is gratefully acknowledged. Finally, the NASA illustration artwork of Mr. Joey Ponthieux (Figs. 1-2) is also acknowledged.

\section{References} 2005.

${ }^{1}$ Young, L.A., Pisanich, G., and Ippolito, C., "Aerial Explorers,” $43^{\text {rd }}$ AIAA Aerospace Sciences Meeting, Reno, NV, January

${ }^{2}$ Clough, B., "Metrics, Schmetrics! How the Heck Do You Determine a UAV's Autonomy Anyway," Proceedings of the Performance Metrics for Intelligent Systems Workshop, Gaithersburg, Maryland, 2002.

${ }^{3}$ Akao, Y., ed., Quality Function Deployment (QFD): Integrating Customer Requirements into Product Design, Productivity Press, Cambridge, MA, 1990.

${ }^{4}$ Aungst, S., Barton, R., and Wilson, D., "The Virtual Integrated Design Method,” ISBM Report \# 6-2001, Pennsylvania State University - Institute for the Study of Business Markets (ISBM), 2001.

${ }^{5}$ Bolt, A. and Mazur, G.H., "Jurassic QFD: Integrating Service and Product Quality Function Deployment," Eleventh Symposium on Quality Function Deployment, Novi, Michigan, June 1999.

${ }^{6}$ Brown, N., et al, "Conceptual Design of a Titan Helicopter and Architecture," Georgia Institute of Technology Student Paper, 2004.

${ }^{7}$ Yetter, J., et al, "High Altitude Long Endurance (HALE) Capabilities and Technology Needs for Earth and Space Science Research", NASA TM X-(pending), 2005.

${ }^{8}$ Raymer, Daniel, Aircraft Design: A Conceptual Design Approach, $3^{\text {rd }}$ Edition, AIAA Education Series, American Institute of Aeronautics and Astronautics, Reston, VA, 1999.

${ }^{9}$ Turing, A.M., "Computing Machinery and Intelligence," Oxford University Press on behalf of MIND (Journal of Mind Association) - A Quarterly Review of Psychology and Philosophy, Vol. LIX, No. 236, pp. 433-60, 1950.

${ }^{10}$ Cooper, G.E. and Harper, Jr., R.P., "The Use of Pilot Rating in the Evaluation of Aircraft Handling Qualities," NASA TN D-5153, April 1969.

${ }^{11}$ Ippolito, C., Pisanich, G., and Young, L.A., "Cognitive Emotion Layer Architecture for Intelligent UAV Planning, Behavior and Control," IEEE Aerospace Conference, Big Sky, MT, March 2005.

${ }^{12}$ Young, L.A. and Pisanich, G., "Aerial Explorers and Robotic Ecologies," Second International Conference on Computing, Communication and Control Technologies, Austin, TX, August 14-17, 2004.

${ }^{13}$ Pisanch, G., Young, L.A., Ippolito, C., Plice, L., Lau, B., “Actions, Observations, and Decision-Making: Biologically Inspired Strategies for Autonomous Aerial Vehicles," AIAA Aerospace Sciences Conference, Intelligent Systems Session, Reno, NV, January 2004.

${ }^{14}$ Plice, L., Pisanich, G., Lau, B., and Young, L., "Biologically Inspired Behavioral Strategies for Autonomous Aerial Explorers on Mars,” 2003 IEEE Aerospace Conference, Big Sky, MT, March 8-15, 2003.

${ }^{15}$ Rhew, R., et al, "Planetary Flight Vehicles (PFV): Technology Development Plans for New Robotic Explorers," AIAA Infotech@Aerospace Conference, Arlington, VA, September 2005.

${ }^{16} \mathrm{http}: / /$ www.nasa.gov/centers/dryden/research/civuav/index.html

${ }^{17}$ Schoenung, S., Wegener, S., Frank, J., Frost, C., Freed, M., and Totah, J., "Intelligent UAV Airborne Science Missions," AIAA Infotech@Aerospace Conference, Arlington, VA, September 2005.

${ }^{18}$ Young, L.A., Lee, P., Briggs, G., and Aiken, E., "Mars Rotorcraft: Possibilities, Limitations, and Implications For Human/Robotic Exploration," IEEE Aerospace Conference, Big Sky, MT, March 2005.

${ }^{19}$ Guynn, M.D., et al, "Evolution of a Mars Airplane Concept for the ARES Mars Scout Mission," 2 nd AIAA "Unmanned Unlimited" Systems, Technologies, and Operations, AIAA 2003-6578, San Diego, CA, September 15-18, 2003.

${ }^{20}$ O'Day, S., et al, "Metrics for Intelligent Autonomy," Proceedings of the Performance Metrics for Intelligent Systems (PerMIS) Forum, National Institute of Standards and Technology (NIST), Gaithersburg, MD on August 24 - 26, 2004.

${ }^{21}$ Lewis, A.S. and Weiss, L.G., "Intelligent Autonomy and Performance Measures for Coordinated Unmanned Vehicles," Proceedings of the Performance Metrics for Intelligent Systems (PerMIS) Forum, National Institute of Standards and Technology (NIST), Gaithersburg, MD on August 24 - 26, 2004.

${ }^{22}$ Young, L.A., "Small Autonomous Air/Sea System Concepts for Coast Guard Missions," USCG Maritime Domain Awareness Requirements, Capabilities, and Technology (MDA RCT) Forum, Santa Clara, CA, May 2, 2005.

${ }^{23}$ AIAA Standards Series, "Recommended Practice: Terminology for Unmanned Aerial Vehicles and Remotely Operated Aircraft", Published by AIAA, R-103-2004e, 2004. 